\title{
EL MITO DEL DILUVIO EN LAS CEREMONIAS DE ENTRONIZACIÓN \\ DE LOS GOBERNANTES MAYAS. AGENTES RESPONSABLES \\ DE LA DECAPITACIÓN DEL SAURIO Y NUEVAS FUNDACIONES
}

\author{
Ana García Barrios \\ Universidad Rey Juan Carlos, Madrid
}

\begin{abstract}
Resumen: El desciframiento de los textos de la Plataforma Jeroglífica del Templo XIX de Palenque corroboró que la visión clásica del mito de la inundación era semejante a la de ciertos textos coloniales, en cuanto a señalar al protagonista como un cocodrilo celeste.

Tras ser decapitado, sobre su cuerpo se colocaron los cuatro árboles del mundo para levantar y sujetar el cielo. Las fuentes coloniales aclaran que, después, un ser sobrenatural pisó la espalda del reptil. Esta acción se ha interpretado como una fecundación que marcaba el comienzo de un nuevo tiempo; sin embargo, F. Scandar (2010) argumenta que la acción de pisar no remite aquí a fecundar, sino a fundar, y fue representada en Mesoamérica con huellas de pies. Es en esta secuencia del mito, desde la decapitación (muerte y fin de caos) hasta la acción de pisar (reorganización del nuevo mundo), donde se focaliza nuestro interés en los monumentos de acceso al trono, en los cuales se advierten unas pisadas que ascienden y cruzan la imagen atrapada del cocodrilo. El ensayo propone que los señores mayas prehispánicos, al subir al trono, se visualizaban como héroes míticos victoriosos que daban muerte al saurio responsable de la inundación (caos) y como fundadores de un nuevo mundo.
\end{abstract}

Palabras Clave: inundación, Cocodrilo Venado Estelar, gobernantes, Clásico maya, Chilam Balam, huellas de pie.

AвSTRACT: The decipherment of texts from the Hieroglyphic Platform of Temple XIX at Palenque confirmed that the classical version of the flood myth was similar to that of certain colonial texts, highlighting the protagonist as a celestial crocodile who caused the flooding of the land and then was beheaded. On his body were placed the four world trees to lift and hold the sky. Then, a supernatural stood on the decapitated reptile. This action has been interpreted as a fecundation ritual that marked the beginning of a new era; however, F. Scandar (2010) argues that the action of standing does not refer here to fertilize, but to found or establish, an action represented in Mesoamerica with footprints. It is in this sequence of myth - from decapitation (death and chaos) to the action of stepping on (reorganization of a new world)-, where our interest is focused on the monuments of accession to the throne, with ascending footsteps that cross the captive crocodile image. This essay suggests that during the accession to throne prehispanic Maya lords were displayed as victorious mythical heroes who brought death to the saurian responsible for flooding (chaos) and as founders of a new world.

KeYwords: flood, Starry Deer Crocodile, ruler, Chilam Balam, Classic Maya, footprints. ReCEPCIÓn: 14 de mayo de 2014.

ACEPTACIÓn: 30 de junio de 2014. 


\title{
EL MITO DEL DILUVIO EN LAS CEREMONIAS DE ENTRONIZACIÓN DE LOS GOBERNANTES MAYAS. AGENTES RESPONSABLES DE LA DECAPITACIÓN DEL SAURIO Y NUEVAS FUNDACIONES
}

\author{
Ana García Barrios \\ Universidad Rey Juan Carlos, Madrid
}

Entonces Dios dijo a Noé: "He decidido el final de toda carne, porque la tierra está llena de violencia por culpa de ellos. He aquí que los destruiré junto con la tierra $[\ldots]$ yo voy a traer un diluvio de aguas sobre la tierra $[\ldots]$ Todo lo que hay en la tierra morirá".

Génesis, 1:6:9-1:6:22.

[...] tuvieron hijos los muñecos de palo; pero no tenían alma, ni entendimiento, no se acordaban de su Creador [...] ya no se acordaban del Corazón del Cielo y por eso cayeron en desgracia [...] en seguida fueron aniquilados, destruidos y [...] recibieron la muerte. Una inundación fue producida por Corazón del Cielo, un gran diluvio se formó, que cayó sobre las cabezas de los muñecos de palo.

Popol Vuh, 1984: 29-30.

\section{Introducción}

Con el desciframiento de los textos prehispánicos del Pedestal ${ }^{1}$ o Plataforma ${ }^{2}$ Jeroglífica del Templo XIX de Palenque (Stuart, 2000, 2005; Velásquez, 2002b,

\footnotetext{
${ }^{1}$ Esta estructura en el texto jeroglífico es mencionada como okib', siendo ok, "pie", e $i b$ ', el instrumental; por tanto, es el pie que sujeta algo. Así, Alfonso Lacadena sugiere que el nombre correcto sería "pedestal" (com. pers., 2014).

${ }^{2}$ Aunque se ha señalado que a esta estructura en el texto se le define okib', "pedestal", en este trabajo será mencionada como Plataforma, ya que en la edición del libro de Stuart (2005) figura como "platform", término que Jorge Pérez traduce en la versión castellana como "plataforma". Por su parte, Paul Gendrop, en su diccionario de términos, explica que "plataforma" se define como "superficie elevada, plana y lisa, usualmente desgajada en todo su perímetro exterior, que constituye la cara superior de un terraplén, ya sea que permanezca descubierta o sirva de terraplenado elevado sobre el cual se desplantan una o varias construcciones; se trata de uno de los elementos básicos de la arquitectura mesoamericana, especialmente en exteriores, donde reviste a menudo un carácter ceremonial" (2009: 161). Mientras que "altar" valdría por "monumento dispuesto para quemar incienso, inmolar a la víctima u ofrecer algún otro tipo de sacrificio" (ibid.: 18). Para Altar plataforma, el autor apunta que "en Mesoamérica, [es una] plataforma o macizos de mampostería, de planta cuadrangular o circular que, provista de una o varias escaleras, se levanta en el centro de una plaza, al pie o en el interior de un edificio, o que sobresale del volumen de una banqueta adosada a un muro. También designa a los monolitos lisos o labrados en altorrelieve o bajorrelieve que —en forma de grueso tambor, de una cabeza fantástica, de un ser fantásico u otra - acompañan algunas estelas, y cuya función pudo ser, en algunos casos, la de un trono o podio" (id.). Banca: "asiento de madera, sin respaldo y a modo de mesilla baja. // 2. Am. Banco. // 3. Méx. Asiento —integral o adosado— hecho de fábrica. v. banqueta, poyo" (ibid.: 30).
} 
2007), se corroboró que la visión clásica del mito de la inundación era prácticamente igual a la expuesta en los textos coloniales, pues coincidían en señalar al protagonista principal como un ser monstruoso que tomaba forma de cocodrilo ${ }^{3}$ celeste y arrojaba por su boca un copioso torrente de agua cargado de elementos con los que produjo la inundación de la tierra. ${ }^{4}$ Como describen las glosas palencanas, el saurio sería decapitado, hecho que coindice con lo descrito en los relatos del Chilam Balam de Chumayel (Mediz Bolio, 2001). La narrativa comienza con un cataclismo producido por un lagarto que vomita el fluido que anega la tierra. A continuación, los propios dioses decapitan al reptil y se detiene la inundación. Posteriormente, el cuerpo del reptil cae sobre la tierra, y sobre sus cuatro esquinas se colocan los cuatro árboles del mundo para levantar y sujetar el cielo caído.

Imágenes del Preclásico Tardío (400 a.C.-250 d.C.), así como textos posclásicos y coloniales también coinciden en indicar que, después de esta inundación, se colocan cuatro árboles en las cuatro esquinas del mundo para levantar el cielo. Las fuentes coloniales aclaran que, a continuación, un ser sobrenatural llamado Uuc Cheknal viene de la séptima capa de la tierra y pisa la espalda decapitada de Itzam Cab Ain (Mediz Bolio, 2001: 88), nombre que recibe durante el Posclásico el lagarto de la inundación de los monumentos clásicos. Esto siempre se había interpretado como una fecundación, aquella que originaba el comienzo del nuevo tiempo. Sin embargo, nuevas revisiones de algunos fragmentos de textos coloniales apuntan a que remite más bien a una fundación (Scandar, 2010), una acción muy representada en Mesoamérica generalmente con huellas de pies en los monumentos que aluden a fundación, toma de territorio y posesión. Es en esta secuencia del mito, desde la decapitación (muerte y fin de caos) hasta la acción de pisar (reorganización del nuevo mundo), donde se focaliza nuestro interés, pues en los monumentos de acceso al trono se advierte, además de la presencia del lagarto de la inundación, unas pisadas que ascienden y cruzan la imagen atrapada del cocodrilo, que han sido hasta ahora interpretadas como huellas de sangre de un sacrificado.

\footnotetext{
${ }^{3}$ Nota del editor: si bien se respetó la variabilidad en los términos empleados para designar al saurio (cocodrilo, caimán, lagarto) — que corresponde por lo común a los nombres consignados en las obras a que remite la autora-, cabe recordar que, desde un punto de vista estrictamente biológico, aunque los tres forman parte del orden Crocodilia, caimanes y lagartos se adscriben a la familia Alligatoridae, mientras que las distintas especies de cocodrilos integran la familia Crocodylidae.

${ }^{4}$ En la literatura mesoamericana suele hacerse referencia a este acontecimiento como "mito del diluvio", pero hay que ser cautos, ya que el término "diluvio" está estrechamente asociado a los acontecimientos históricos descritos en el Poema de Gilgamesh, de tradición babilónica, y en los relatos bíblicos del Antiguo Testamento. Resulta pues importante puntualizar que aunque aquí se hable de diluvio en alternancia con inundación, las referencias exactas clásicas y en las entradas en el Diccionario maya yucateco para b'ulk'abal se traducen como "anegar o echar a fondo, inundación” (Barrera, 1980: 69). Por tanto, la expresión correcta sería inundación; se emplea también diluvio simplemente para indicar al lector que la inundación maya implicó la anegación de la tierra y el cataclismo del mundo establecido.
} 
Aquí se propone que, cuando accedían al trono, los mayas prehispánicos se visualizaban como los héroes míticos victoriosos que dan muerte al saurio que produce la inundación (caos) y como restauradores del nuevo orden, fundadores del nuevo mundo. Esta recreación mítica de la construcción del mundo servía como metáfora del ordenamiento y fundación de su reinado. Acción que quedaba expresada con las huellas de pie al pisar el territorio controlado. Trasladaban de esta manera un tiempo mítico, en el que se crea el mundo, a su tiempo histórico, en el que arriban al poder, como claramente se advierte en el texto y la representación del Templo XIX de Palenque, explicado más adelante.

Para este estudio han sido imprescindibles los datos aportados por investigaciones que desde al año 2000 están arrojando luz sobre este tema. Destacan los trabajos llevados a cabo por David Stuart en 2000 y 2005 sobre el Templo XIX de Palenque, los de Erik Velásquez sobre los agentes del diluvio (2002 y 2007), los realizados sobre los murales de San Bartolo (Taube et al., 2010), y los de Florencia Scandar, quien en el 2010 hizo una nueva propuesta a las interpretaciones tradicionales sobre la cópula que se producía entre Uuc Cheknal y la espalda del lagarto para dar forma al nuevo mundo.

Con la revisión de esos y otros trabajos se pretende arrojar algo más de luz sobre quiénes fueron los agentes que participaron en el mito de la inundación, así como el orden de los acontecimientos acaecidos, y el porqué, cómo y para qué utilizaron los gobernantes el programa iconográfico del Cocodrilo Celeste, unido a la acción de pisar señalada en los monumentos clásicos con huellas de pies, y descrita en textos coloniales. ${ }^{5}$

\section{El uso del tiempo mítico en un tiempo histórico entre los antiguos mayas: el mito del diluvio}

Conocemos por los documentos indígenas coloniales, los códices prehispánicos $\mathrm{y}$, en muchos casos, por los textos y registros arqueológicos, que las distintas culturas mesoamericanas tenían una preocupación constante por el tiempo. Al contrario de nuestro concepto de tiempo, netamente lineal y heredado de las tradiciones próximo-orientales, los pueblos mesoamericanos concebían el tiempo como algo cíclico; la historia y los acontecimientos pasados en un momento dado se debían repetir (Girard, 1962: 45; Velásquez, 2010: 58). La opinión de López Austin (2009: 9) es que el tiempo mítico es una especie de tiempo simultáneo, donde no hay pasado, presente, ni futuro, y cambia cuando, después de la inundación, el mundo es ordenado y el cielo sustentado por los cuatro árboles cósmicos y se produce una nueva fundación de la tierra. En ese momento comienza un

\footnotetext{
${ }^{5}$ De forma muy especial deseo agradecer a Erik Velásquez García los comentarios y sugerencias sobre el mito de la inundación, a Florencia Scandar por facilitarme su tesis de licenciatura, a Alfonso Lacadena por sus comentarios siempre certeros, a Christophe Helmke por su apoyo en la traducción del resumen y comentarios, y a Mario Humberto Ruz por sus observaciones y la corrección de estilo del texto.
} 
tiempo mundano que nos rige, y cuya característica principal y diferenciadora con el tiempo anterior es que hay devenir entre pasado, presente y futuro. Es decir, es un tiempo lineal.

Con este concepto de final de un tiempo anterior y principio de un nuevo periodo es con el que se asociaron los gobernantes mayas cuando figuran con el reptil que protagoniza la inundación y destrucción del mundo anterior. Así se advierte en las imágenes y representaciones de los monumentos de entronización desde el periodo Preclásico. Como apunta C. Helmke (2012a, 2012b), la intención de los gobernantes era extraer el pasado mítico y transportarlo al ámbito del presente histórico. Un tiempo antiguo con el que daba origen el nuevo tiempo, un tiempo mítico que los señores mayas hacían confluir con su tiempo histórico.

Esta concepción de tiempo mítico unido al tiempo histórico todavía es empleada por la mayoría de los pueblos mesoamericanos; en los procesos rituales existe una sincronía entre una temporalidad mítica y el presente. Como explica Neurath (2000: 58) al referirse a los huicholes, la comunidad regresa a sus orígenes, lo que significa que los acontecimientos narrados en los mitos de creación vuelven a suceder. Probablemente en la época prehispánica, como en la actualidad, tampoco había una representación del mito en el sentido teatral, sino una identificación entre significante y significado, ya que no era una acción imitativa, sino que se recreaba el suceso mismo. Es, como apunta Cassirer (1925: 64) un drómenon, un acontecimiento real y efectivo, sin ceremonias.

Precisamente por ser efectivo, los señores mayas alternaban, e incluso superponían, el tiempo histórico con el tiempo del mito de la inundación en los eventos más relevantes de su vida. Entre otros, cabe destacar el momento de acceso al trono, o la conmemoración de finales de periodos de 20 años o k'atun (Velásquez, com. pers., 2011). En este sentido, Stuart (en Taube et al., 2010) sugiere que estos ciclos de final de tiempo también aluden a la toma de poder del gobernante, lo que encaja perfectamente con el empleo del mismo mito. Además, el Cocodrilo Celeste está también asociado a fechas que señalan el comienzo de temporada de lluvias, festividades de año nuevo y, como era de esperar, a la fecha mítica 4 Ajaw 8 Kumk'u (agosto de 3114 a.C.), con la que da comienzo el cómputo del tiempo maya (Velásquez, 2002b: 430-432). Entonces, la figura del saurio funcionaba como símbolo del fin de una etapa anterior y el principio de una era, etapa, periodo, estación de lluvia o un reinado nuevos. En este trabajo sólo se analizará el empleo del mito de la inundación en el contexto de acceso al trono, siendo el punto central dos episodios del mito: la decapitación del reptil celeste, y la acción de pisar su cuerpo, caído y abatido sobre la tierra, para formar el nuevo mundo.

\section{Evolución iconográfica del lagarto de la inundación}

Los antiguos mayas representaron al agente de la inundación en numerosos monumentos desde el Preclásico Tardío hasta el Posclásico, un periodo largo en el 
que la entidad celeste que encarna el diluvio va cambiando en su aspecto físico. Su imagen varía según la época, el soporte y la región, pero su estudio iconográfico permite saber que efectivamente aquel ser de los murales preclásicos de San Bartolo es el mismo que fue representado 1500 años más tarde en el Códice Dresde.

Erik Velásquez (2002b) realizó un detallado trabajo diferenciando iconográficamente las acciones de diferentes seres híbridos que en el área maya se conocían con el nombre genérico de Monstruo Cósmico. Éste, en las primeras representaciones del periodo Preclásico Tardío (400 a.C.-250 d.C.), tiene aspecto de serpiente de doble cabeza y en ocasiones su cuerpo celeste aparece con signos de astros (Velásquez, 2002b: 419). Durante el Clásico Temprano su fisonomía se modifica y se añaden motivos iconográficos de alto contenido simbólico, se reconoce en los monumentos como un cocodrilo de doble cabeza con cuerpo celeste, ojo de estrella y patas de venado, por lo que es conocido en la literatura como Cocodrilo Venado Estelar (Velásquez, 2002b: 419-425; 2007: 2; Stuart 2005: 70-75). Velásquez (id.) sostiene que la cabeza del saurio con el signo de ojo de estrella representa a Venus.

En el Clásico Tardío se mantendrá este diseño, pero se incorporará definitivamente en la cabeza trasera y descarnada del cocodrilo un complejo iconográfico conocido como monstruo cuatripartito, por portar las cuatro insignias rituales en el plato de sacrificio empleado por los mayas clásicos. El plato contenía el signo solar, una espina de mantarraya relacionada con el sacrificio, una concha asociada con los espacios acuáticos, y un manojo de plumas con el signo que, según Velásquez (2002b: 419-424), se lee way, y estaría en relación con el inframundo. Esta cabeza suele ubicarse en el extremo oriental, y Schele (1976: 20) propuso que podría referirse al Sol naciente. Por su parte, Ignacio Cases (com. pers., 2014) considera que la insignia en sí misma puede aludir al Sol nocturno. Desde nuestra perspectiva encuentra más sentido esta última opinión, por la ubicación de los elementos sacrificiales que, pese a que irían destinados al nacimiento del Sol, tendrían lugar en un escenario nocturno, como parece mostrar toda la banda celeste y los signos de astros que forman el cuerpo del reptil.

En ocasiones, a lo largo del periodo Clásico (250-900 d.C.), ese cocodrilo es representado sin cabeza posterior y sin insignia cuatripartita, como se pintó en el Vaso de los Siete Dioses. También sus acciones varían. En ciertas circunstancias se le figuró vomitando un líquido que arrastraba objetos e insignias preciosas, y, en otras, sin expulsar fluido alguno. Por supuesto, también se le muestra atado y atrapado por el gobernante que se sienta sobre él. Durante el Posclásico pierde definitivamente la insignia cuatripartita y en muchos casos la cabeza trasera. Durante este periodo se mantiene la tradición de representarlo atado en contextos mitológicos, como se ve en las estelas de Mayapán o en los manuscritos posclásicos. En este sentido, como señala De la Garza (2008), también existen referencias escritas en algunos documentos coloniales que aluden a que se ataba y se quemaba. 
Por otro lado, cabe señalar que, aunque el cocodrilo sea decapitado, tal y como cuentan los documentos coloniales y el texto jeroglífico del Pedestal o Plataforma del Templo XIX de Palenque (Stuart 2000; 2005), nunca se representa en esas circunstancias. Visualmente, lo que más se aproxima a una decapitación podría ser la cabeza trasera descarnada del cocodrilo, que podría aludir a su muerte, y, tal vez, la imagen del cocodrilo en el Vaso de los Siete Dioses, donde se está creando el nuevo mundo, y el saurio — recostado en la techumbre de la caverna donde se encuentra la deidad creadora, en este caso el anciano Dios Lporta en el cuello un collar de ojos, que siempre se ha asociado con la muerte.

\section{Diferentes formas de representar al cocodrilo de la inundación en escenarios de toma de poder}

Esta narrativa mítica, tan relevante para los antiguos mayas, se representó en diferentes soportes desde el Preclásico Tardío (400 a.C.-250 d.C.) hasta el Posclásico (1000-1500 d.C.), eligiendo según los momentos una parte u otra del episodio. Así vemos que en ocasiones el cocodrilo ejerce de bóveda celeste y arroja vómito por su boca, y en otras, está abatido y atado en el andamiaje de los soberanos.

Igualmente, los soportes donde se expresó este acontecimiento diluvial fueron muy variados, tanto en muros de los edificios modelados en estuco o pintados con narrativas, como en altares, estelas, vasijas pintadas y manuscritos, lo que indica que fue un mito muy recurrido. Algunos de estos soportes, como las vasijas o las pinturas murales, permiten ser más prolijos en detalles y que la narrativa del mito sea más extensa que en las estelas, monolitos destinados a ensalzar la figura del soberano y sus logros. Por eso, en los monumentos en piedra la alusión a la inundación se señala simplemente de forma visual mediante la representación del cocodrilo celeste. Éste ejerce de pars pro toto del mito, y seguramente la historia completa fuese conocida por todos aquellos que lo veían. Al igual que en nuestra cultura al ver un crucifijo somos capaces de reconstruir toda la historia de Jesús, desde su nacimiento hasta su muerte, suponemos que lo mismo ocurriría al visualizar la representación del reptil anegando la tierra o bien torturado y atado; un mito entonces completo que ahora cuesta reconstruir en todos sus detalles.

Tras explicar el cambio evolutivo que fue sufriendo la figura del cocodrilo cósmico desde el Preclásico Tardío hasta el Posclásico, añadiendo algunos argumentos a los analizados por Velásquez en 2002, abordaremos las formas de representar al saurio a lo largo del tiempo, en los escenarios relativos a la toma de poder del soberano.

Durante el Preclásico fue habitual mostrar al reptil de forma simultánea conformando la bóveda celeste y, a la vez, abatido como parte de la tierra. Esto no resulta extraño si entendemos que los mayas de entonces, al igual que los de ahora, eran duales, opuestos y al mismo tiempo complementarios. Así, el mismo monstruo celeste es a la vez el que conforma la superficie terrestre. En este mo- 
mento tan temprano las escenas suelen desarrollarse sobre la espalda del saurio, como se ve en los murales de San Bartolo explicados más adelante, o en el Altar 12 de Takalik Abaj (figura 1) que, pese a ser una ciudad ubicada en la región mixezoque, comparte el mito de la inundación, del cual hicieron uso sus soberanos de la misma manera que sus vecinos mayas. En este momento del Preclásico, el soberano de San Bartolo se muestra el día de su entronización formando parte del mito de la inundación sentado en un pódium formado por andamios, una retórica que se repetirá también en las representaciones de los señores del Clásico Tardío, sólo que para entonces el cocodrilo se encuentra abatido, atado y sometido, formando parte de la decoración de esos andamios.

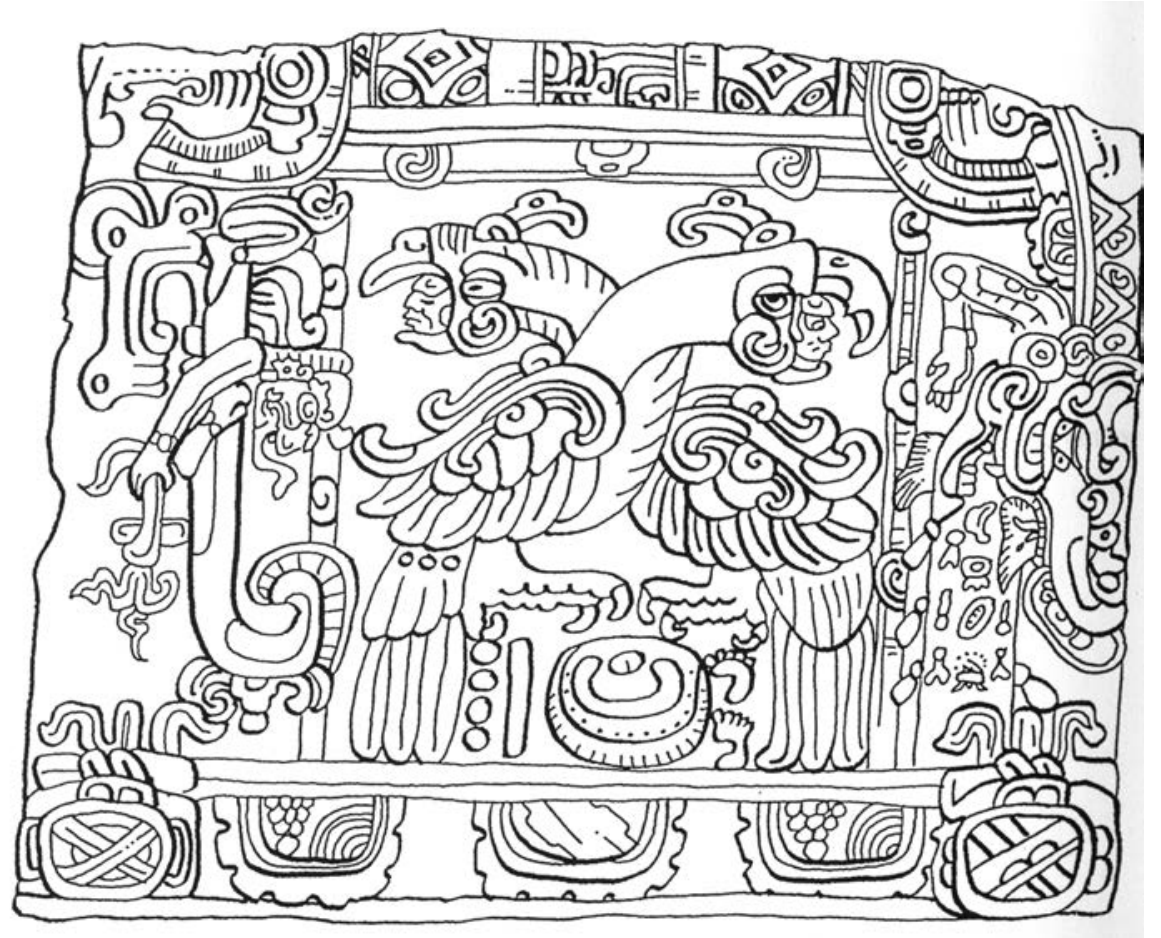

Figura 1. Altar 12 de Takalik Abaj

Durante el Clásico Temprano el dragón de la inundación suele mostrarse arqueado sobre los gobernantes o sus nombres en emblema, como ocurre en la estructura Margarita de Copán (figura 2). Como decimos, los soberanos del Clásico Tardío y Posclásico fueron más explícitos y efectistas a la hora de mostrarse en monumentos públicos. El día de su acceso al trono los señores eligieron generalmente representarse sentados sobre los reptiles abatidos y maniatados en las escaleras que tenían que recorrer para subir el trono. 


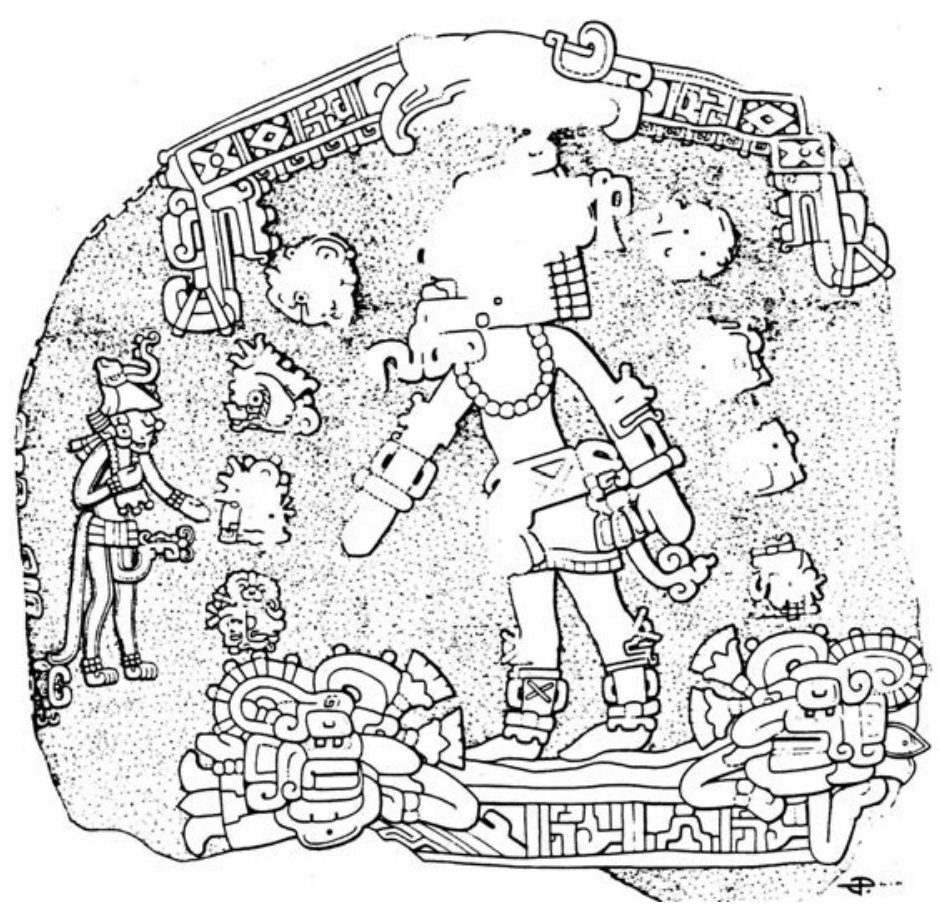

FigurA 2. Estructura Margarita, Copán

En Palenque la forma elegida para mostrar este control fue diferente y novedosa, pues sus dirigentes gustaban distinguirse del resto de reinos por mostrar el tiempo mítico especialmente unido a los acontecimientos históricos. En la Plataforma Jeroglífica del Templo XIX, Ahku'l Mo' Naahb' III se muestra encarnando a GI, uno de los dioses principales de Palenque y responsable, según los textos que acompañan al bajorrelieve, de dar muerte al saurio. Como explicamos a continuación, es la misma estrategia, aunque empleada de diferentes formas visuales.

\section{Agentes responsables de la decapitación del lagarto de la inundación}

Los reyes de Palenque mostraron un gusto especial por las representaciones de acontecimientos mitológicos. El descubrimiento de la Plataforma Jeroglífica del Templo XIX (figura 3a) con la inscripción que menciona la decapitación del Cocodrilo Venado Estelar permitió corroborar la versión clásica del mito del diluvio. El texto alude a un momento pre-era cercano a la fecha mítica 4 Ajaw 8 Kumk'u que señala el comienzo del mundo conocido. El gobernante Ahku'l Mo' Naahb III elige el pasaje de la decapitación del Caimán celeste para señalar el comienzo de un nuevo tiempo que inicia con su reinado. Los acontecimientos descritos en este pasaje no son casuales si atendemos a la iconografía que presenta el rey (Stuart, 


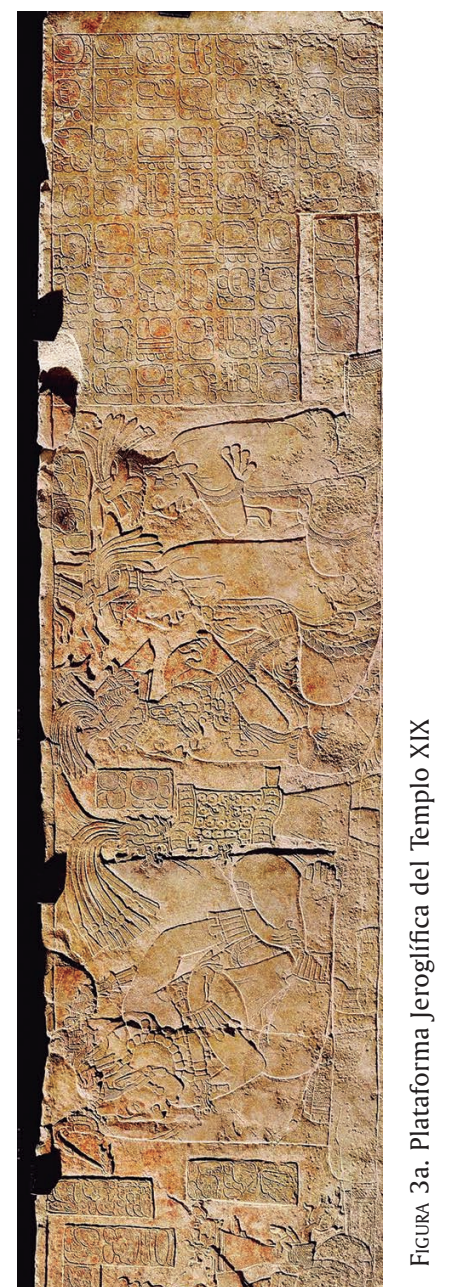


2000, 2005; Velásquez, 2007). Es posible que el texto de la Plataforma del Templo XIX permita poner un poco de orden en los hechos acaecidos en el mito de la inundación (Stuart, 2000, 2005; Velásquez, 2002b, 2007). El texto comienza con la fecha en que se corta la cabeza del Cocodrilo de espalda pintada o escrita, y continúa diciendo "copiosamente fluyó la sangre del que levanta la corriente", una sangre que se ha interpretado como un diluvio de sangre, pero que más bien podría aludir a la sangre que brota de la cabeza decapitada del cocodrilo, sangre del ser sacrificado y muerto, el ser que ha levantado la corriente o ha producido la inundación.

Como apunta Stuart (2005: 177) todo parece señalar a GI como el agente encargado de decapitar al cocodrilo. No por casualidad se presenta el gobernante Ahku'l Mo' Naahb III en esta Plataforma recibiendo el poder ataviado con los atributos del dios GI, especialmente apreciable en su tocado (figura 3b). Emblemas que indican que está encarnando al dios y sus acciones. Lo que da sentido al hecho propuesto de que el soberano es el decapitador o verdugo del cocodrilo en el momento de su entronización. El rey Ahku'l Mo' Naahb III no se muestra en una estela sentado sobre el cocodrilo atado, recordemos que Palenque es una ciudad donde las estelas no fueron los monumentos empleados para expresar el poder real, por eso apenas se han registrado arqueológicamente, pero el rey, aunque emplea otro recurso visual, lanza el mismo mensaje que los señores de otras ciudades, con estelas que siguen el patrón diseñado con el rey sentado sobre el cuerpo abatido del saurio.

En este caso Ahku'l Mo' Naahb III es el controlador el nuevo tiempo que se origina tras la decapitación del reptil ejecutada por Gl. Así, es el rey el que está fundando el nuevo orden, el nuevo mundo, el nuevo tiempo que regirá bajo su gobierno, y ha elegido encarnar y personificar a GI en la Plataforma precisamente porque éste actúa como agente de la decapitación. Con esta acción superpone el tiempo mítico a su tiempo actual, a su tiempo histórico.

Suponemos que esta misma intención tuvieron los señores del periodo Clásico que se mostraron sobre el reptil en los monumentos de entronización. Así como los soberanos que en los murales de San Bartolo se están entronizando y formando parte activa de la narrativa completa del mito de la inundación.

También se ha recuperado una figurilla de Jaina que representa al dios GIII sentado sobre un cocodrilo con una oquedad en su lomo, al que agarra y retiene por el hocico mientras blande su hacha (figura 4) (Martos, 2010: 280-281). En este caso hay que preguntarse ies posible que GIII también fuese uno de los agentes encargados de la decapitación del lagarto o que en cada reino se emplease al dios patrono como responsable de la muerte del saurio? Posiblemente no hubo un único agente responsable de la muerte del lagarto, pues asociado a esta acción aparece, además de GI y GIII, el dios Chaahk, en la fachada Margarita (ver figura 1).

Los gobernantes debieron elegir según sus preferencias quién era el agente responsable de la muerte del cocodrilo y por supuesto es lógico que variase según la región y la época. ¿Quién mejor que el dios protector de una ciudad para ser el responsable de acabar con el tiempo anterior y dar comienzo a un nuevo reino? 
En esencia, la representación de este lagarto es un tema constante en el tiempo y en el espacio, que hace reflexionar sobre su importancia en las cuestiones políticas y el uso de este mito en éstas.

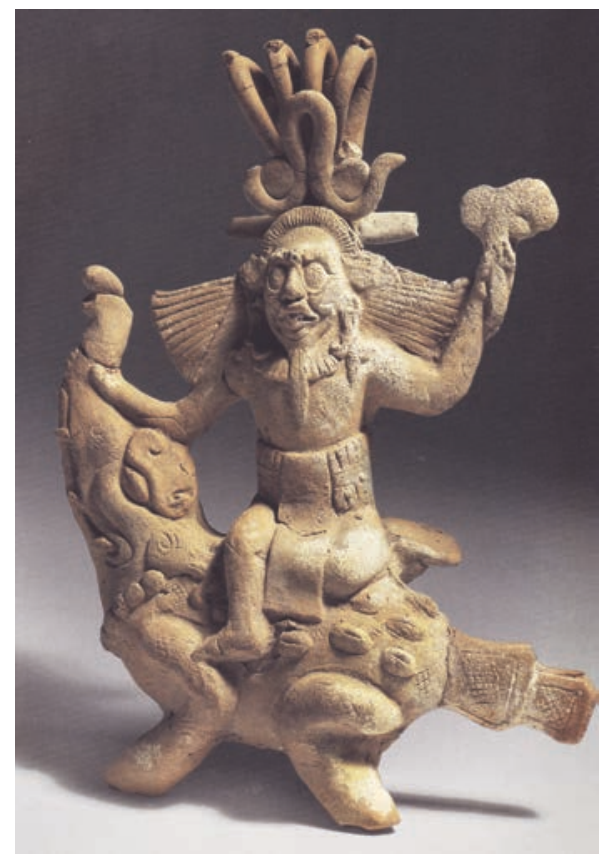

FIGURA 4. GIII sentado sobre un cocodrilo

El cocodrilo de la inundación y las huellas de pies en los documentos coloniales

En los monumentos clásicos los gobernantes mayas aparecen sentados sobre el cocodrilo atado y pisado. En el centro de este reptil sometido se observan unas huellas de pies, que han sido interpretadas como el camino que lleva al gobernante al trono y que están manchadas de sangre por el sacrificio de algún cautivo, el cual en ocasiones aparece representado en la parte inferior de la estela, acto que era imprescindible en los rituales de entronización, como se observa especialmente en las estelas de Piedras Negras (Martin y Grube, 2002: 149).

En la escritura maya hay pocos glifos que incluyan como referente gráfico el pie humano. En estos casos lo que indican son acciones relacionadas con el traslado de un lugar a otro, que en esencia expresan la idea de caminar. De hecho el glifo hul, "llegar", en ocasiones se diseñó con el icono de la huella de pie (Bernal y Velásquez, 2005: 33). También se advierten formas glíficas de huellas de pie ascendiendo por escaleras que se leen $t a b$ ' y cuyo significado es "subir o ascender". En este sentido, la huella de pie como verbo de acción de desplazamiento 
se remonta a la cultura olmeca (Lacadena, 2008: 607-626), aunque estas pisadas también caben en otros campos semánticos relacionados con llegada, conquista y cautiverio, como parecen expresar las escenas de reyes o reinas pisando a cautivos $^{6}$ (ver Bernal y Velásquez, 2005: 33; Lacadena, id.; Lacadena y Ciudad, 2009: 59-66). En este sentido, Velásquez (2002a: 235-244, 258) señala que los quichés emplean el verbo quiyik', que significa 'conquista”, y viene de yik' o yek', "pisar", "hollar" (cognado del verbo chek' yucateco), y que también emplean para describir expresiones de conquista en guerra. ${ }^{7}$ Además, el autor advierte que en el Título de Yax se menciona cómo se juntaron en su tierra y "eran sin número las montañas que pisaron y en que caminaron por causa de sus señoríos". El pasaje hace referencia clara a la acción de hollar los terrenos conquistados, en el sentido de añadirlos al nuevo reino fundado.

También las huellas de pies fueron un recurso gráfico muy extendido en la cultura teotihuacana ${ }^{8}$ que, muy posiblemente, al igual que la maya señalaba el territorio que estaba siendo conquistado y a la vez fundando.

Esta acción de pisar la tierra se recoge en libros coloniales como el Chilam Balam de Chumayel (Mediz Bolio, 2001: 87-88), fuente que ha ayudado a entender esta acción en las estelas del Clásico. El documento menciona que "fueron cogidos los Trece dioses, y fue rota su cabeza y abofeteado su rostro y fueron escupidos, y se los cargaron a las espaldas, y fue robada su Serpiente de Vida, con los

\footnotetext{
${ }^{6}$ En el área maya son habituales las escenas en estelas con gobernantes pisando cautivos, que a primera vista sugieren que se trata precisamente de señores que han capturado a un personaje relevante de otro reino (Velásquez, 2002a: 244). La Estela 24 de Naranjo representa a la señora Seis Cielo pisando a un cautivo. Sabemos por los textos que esta reina se desplazó desde Dos Pilas a Naranjo en el año 682 d.C. para fundar un nuevo linaje. Efectivamente, no hay huellas de pie en el monumento, pero sí la acción en sí misma de pisar, que se representa en la estela, así como el término huli, "llegar", que, como refieren Martin y Grube (2002: 74), está imbuido de un sentido más amplio, que abarca la fundación de una nueva dinastía. Tres días después de llegar a Naranjo la señora Seis Cielo visita una pirámide importante para dedicar el santuario y restaurar los fundamentos del reinado. Según apunta García Zambrano (1994, apud Scandar 2010: 72-75), los hitos elevados, pirámides o cerros, son elementos esenciales en las ceremonias de fundación de ciudades. Así, la escena de la Estela 24 de Naranjo puede estar transmitiendo una información mucho más amplia de lo que se ve a simple vista. La acción de pisar podría indicar, además de captura, el control del territorio conquistado y nuevamente ordenado.

${ }^{7}$ Velásquez (2002a: 233-235) señala que los verbos estrella sobre concha, estrella sobre tierra y estrella sobre nombre de lugar que están en las inscripciones, aunque permanecen sin descifrar, son expresiones de conquista. Tal vez por eso no sea casualidad que aparezcan representados dentro de los bultos sagrados en el Vaso de los Siete Dioses y en la Caja de los Once Dioses, vasijas que precisamente están recreando el acontecimiento de la creación del mundo en la fecha mítica 4 Ajaw 8 Kumk'u.

${ }^{8}$ En Teotihuacan un gran número de imágenes con personajes marcando sus huellas de pies se encuentran en pintura mural, pero también hay huellas de pies realizadas en piedra verde, así como decorando las paredes de las vasijas. El mural de la Zona A del Conjunto del Sol reproduce guerreros ataviados con tocados de aves y portando cuchillos con corazones sangrantes que están enmarcados por un camino de pies. En el mural del Patio Blanco del barrio teotihuacano de Atetelco se advierten también dos guerreros ataviados a la manera de Tláloc, armados con dardos y cuchillos con corazones sangrantes, que caminan por los límites de la planta de un templo, cuyo piso está repleto de huellas que se han interpretado como danza (Lombardo, 2006: 36), pero muy probablemente puedan indicar la acción de fundar el templo.
} 
cascabeles de su cola, y con ellas fueron cogidas sus plumas de quetzal”, junto con su semen y sus semillas. Bolon Dzacab lo envolvió todo y lo ató y se fue al decimotercer piso del cielo. El relato del Chumayel continúa asentando:

[...] entonces cayeron su piel y las puntas de sus huesos aquí sobre la tierra $[\ldots]$. Y fueron enterrados en la orilla de la arena, en las olas del mar. Y entonces, en un solo golpe de agua, llegaron las aguas. Y cuando fue robada la gran serpiente, se desplomó el firmamento y hundió la tierra. Entonces los Cuatro dioses, los Cuatro Bacab, lo nivelaron todo. En el momento en que acabó la nivelación, se afirmaron en sus lugares para ordenar a los hombres amarillos (Mediz Bolio, 2001: 88).

Se describe, pues, que la inundación fue producida cuando fue robada la Gran Serpiente, y su piel y las puntas de sus huesos cayeron sobre la tierra. Estos elementos podrían ser la versión colonial de los objetos que arroja el reptil del Clásico. Entonces, de un solo golpe llegaron las aguas, y se desplomó el firmamento y se hundió la tierra. Según Solís Alcalá (1949: 230-231), la destrucción del mundo anterior fue producida por Bolon Ti K’uh, quien mandó a Itzá Cab Ahiin (equivalente posclásico del Cocodrilo Estelar) para que ocasionara la inundación de la tierra, pero el propio dios no permitió que acabara por completo con la creación: cortó la garganta del saurio y con el cuerpo de éste se formó la superficie de nuestro mundo (Velásquez, 2002b: 446-447). La tierra se vuelve a nivelar cuando se colocan los cuatro árboles ${ }^{9}$ en las esquinas. A continuación, un personaje llamado Uuc Cheknal baja de la séptima capa del cielo y pisa la espalda de Itzam Cab Ain. Esta acción había sido interpretada desde los primeros estudios como cópula, hasta la nueva revisión que hizo Florencia Scandar en 2010 (33-53). En su análisis del folio 25r del Chilam Balam de Chumayel y atendiendo a las 50 entradas de la expresión chek, "pisar", recogidas en el Vocabulario de Maya Than (Acuña, 1993), Scandar señala que sólo nueve presentan acepciones relacionadas con copular, mientras que la gran mayoría se refiere a la acción de pisar u hollar. Esto, unido a que en las versiones del Chilam Balam de Maní (Solís Alcalá, 1949) y de Tizimín (Edmonson, 1982) en ningún caso se traduce chek como "fecundar", le lleva a postular que la traducción de esta sección del texto es incorrecta. La autora propone que la acción de pisar alude al sentido de fundar más que al de fecundar, propuesta que seguimos en este artículo.

Así, la tarea de pisar tiene un papel relevante en este entramado de destrucciones y renovaciones, de cocodrilos venado estelares, gobernantes entronizados y huellas de pies, pues es precisamente el señalamiento de éstas la forma gráfica empleada durante la Colonia para expresar la acción de fundar.

Todo esto iría acompañado de los imprescindibles rituales de sangre, como se muestra en algunas narrativas que se explican más abajo. Por último, un ser sobrenatural holla la espalda caída del lagarto marcando el territorio con pisadas

\footnotetext{
9 “El primero que se levantó fue el Árbol Blanco, el árbol del norte. Después se levantó el Árbol Negro, el del oeste. El siguiente árbol que se levantó fue el Árbol Amarillo, el del sur. Posteriormente se levantó el Árbol Rojo, el del sur y por último la Gran Madre Ceiba, en el centro".
} 
que permiten fundar el nuevo mundo. Es posible, como apunta Velásquez (2007: 6; com. pers., 2011), fijándose en los datos de los Libros del Chilam Balam, que posteriormente se descuartizase al reptil coincidiendo con un eclipse, e incluso que se quemase, como parecen sugerir algunas figuras donde aparece con el cuerpo horadado, como se menciona en los textos del Templo XIX de Palenque (Stuart, 2005) que se explicarán más abajo con detalle.

\section{El cocodrilo de la inundación y las huellas de pies en los monumentos mayas: desde el Preclásico al Posclásico}

A continuación se analiza una serie de monumentos donde se advierte la acción de pisar a través de huellas de pie en contextos donde también participa el Cocodrilo Venado Estelar de la inundación. La exposición de los datos se ofrece en forma cronológica, del Preclásico Tardío hasta el Posclásico.

Huellas de pie y el mito de la inundación en las representaciones del Preclásico. Las pinturas del muro poniente de San Bartolo (Petén)

Con todo lo expuesto hasta ahora, creemos reconocer el mito de la inundación desde momentos muy tempranos y en formas muy completas, como es el caso del mural poniente de San Bartolo. Pero antes de adentrarnos en esa narrativa, hay que recordar que, remontándonos en el tiempo al Preclásico, tres siglos antes de nuestra era, se erigió el Altar 12 de Abaj Takalik (Velásquez, 2002b: 419). La composición escultórica es sumamente interesante, pues se advierten la alternancia y simultaneidad de dos secuencias del mito: arriba el saurio de cuerpo celeste de la inundación; abajo el mismo numen ya abatido. En la parte superior se aprecia el contorno de la Deidad Pájaro Principal, como ocurre en otras muchas imágenes del Lagarto celeste (ver Taube et al., 2010: 36-38). El gobernante está sobre él de pie, en una actitud de movimiento, pisando y caminando por su lomo ondulado que bien podría insinuar agua (ver figura 1). La acción de caminar sobre el cuerpo del reptil, como ya se ha dicho, reproducía la fundación del Mundo. Esta escena podría ser una de las primeras representaciones en las que un gobernante se muestra sobre el lagarto en una toma de poder.

Avanzando en el Preclásico, creemos reconocer en el muro poniente de la Pirámide de las Pinturas, en San Bartolo ${ }^{10}$ no sólo al protagonista del mito de la inundación, el lagarto (figura 5), sino tal vez el mito en su narrativa más extensa asociada al ascenso al trono de un gobernante (figuras 6a-6b). Para esta propuesta me baso en el trabajo realizado por el equipo del Proyecto San Bartolo, en el que acertadamente apuntan que en este muro se muestran algunos de los temas relacionados con la creación y el gobierno entre los mayas del Preclásico Tardío.

\footnotetext{
${ }^{10}$ Véanse también los trabajos de Saturno et al., 2005a, 2005b. La propuesta que aquí se esboza es sólo una visión general de lo que podría encontrarse representado en estas pinturas murales.
} 


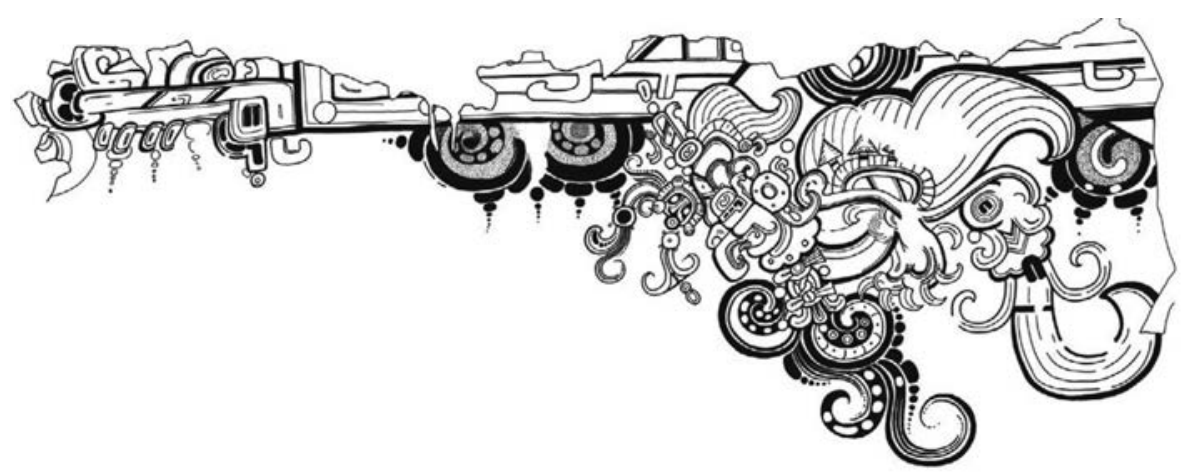

FIGURA 5. Lagarto de la inundación representado en el muro poniente de la Pirámide de las Pinturas, San Bartolo

Resaltan de forma especial la erección de los árboles direccionales asociados con la Deidad Ave Principal, y la parte norte del muro poniente donde se encuentra el ciclo mítico del Dios del Maíz, pero con referencias claras a la institución del gobierno, como indican las dos escenas detalladas de coronaciones reales que ocurren sobre andamios (Taube et al., 2010: 66, 87), de forma muy similar a como se muestra a los gobernantes del Clásico Tardío al tomar el poder.

A mi parecer, en estas escenas, pintadas un siglo antes de nuestra era, se muestra iconográficamente de una forma extensa y completa el tema en cuestión, que no es otro que la utilidad del mito de la inundación como metáfora de creación de un nuevo tiempo en las coronaciones y tomas de poder de los nuevos gobernantes.

Aunque el equipo del proyecto San Bartolo no lo advierte, desde mi perspectiva, en estas pinturas se encuentran también los episodios anteriores a la creación del mundo, los que aluden a la destrucción por una gran inundación. La presencia del lagarto celeste del diluvio representado sobre los árboles direccionales de San Bartolo indica el comienzo del mito. Un ser serpentino de doble cabeza con cuerpo celeste arroja sangre por su boca. Es un personaje similar a los descritos hasta ahora. De su cuerpo celeste emanan nubes y lluvia negra (Taube et al., ibid.). Justo en el centro de este monstruo se encuentra la Deidad Pájaro Principal. Toda la escena del mural se representa apoyada sobre un cuerpo de bandas celestes que posee las mismas características que el lagarto, lo que se puede interpretar como el cuerpo abatido del numen, como suele verse en otros monumentos preclásicos y en otros del Clásico que comentaremos. ${ }^{11}$

${ }^{11}$ A esto hay que añadir que el friso de estuco que se reproduce en la fachada exterior del muro norte del edificio de las pinturas presenta un cuerpo de bandas celestes, que Taube et al. asocian con la Deidad Pájaro Principal (2010: 36, fig. 23), y que desde mi perspectiva podría aludir al momento en que el Lagarto Celeste es abatido, tal vez por este Pájaro, Vukuk Kakix del Clásico, o como mencionan las fuentes coloniales, podría tratarse de Uuc Cheknal, el que vino de la séptima capa de la tierra a pisar la espalda del lagarto. 

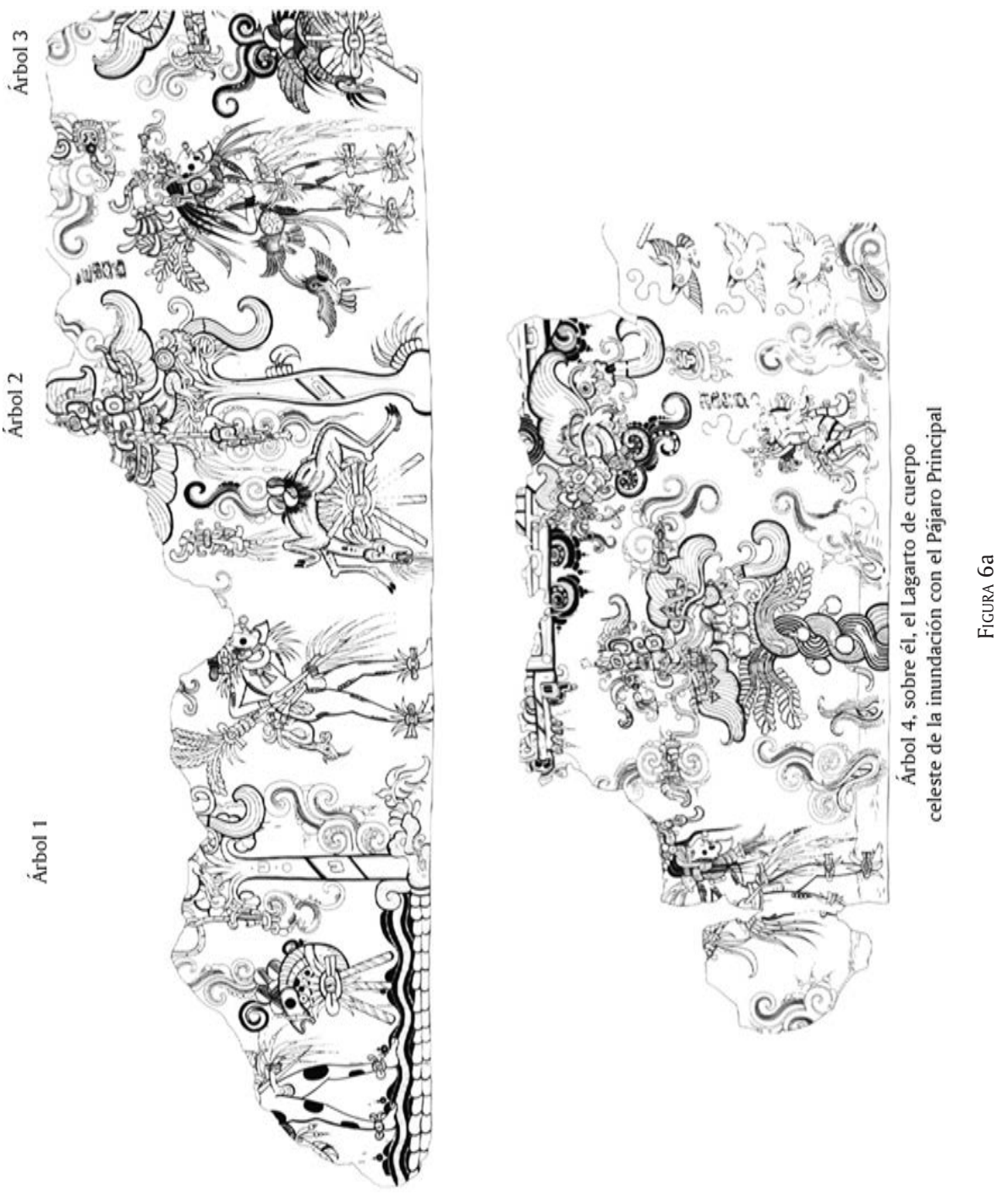

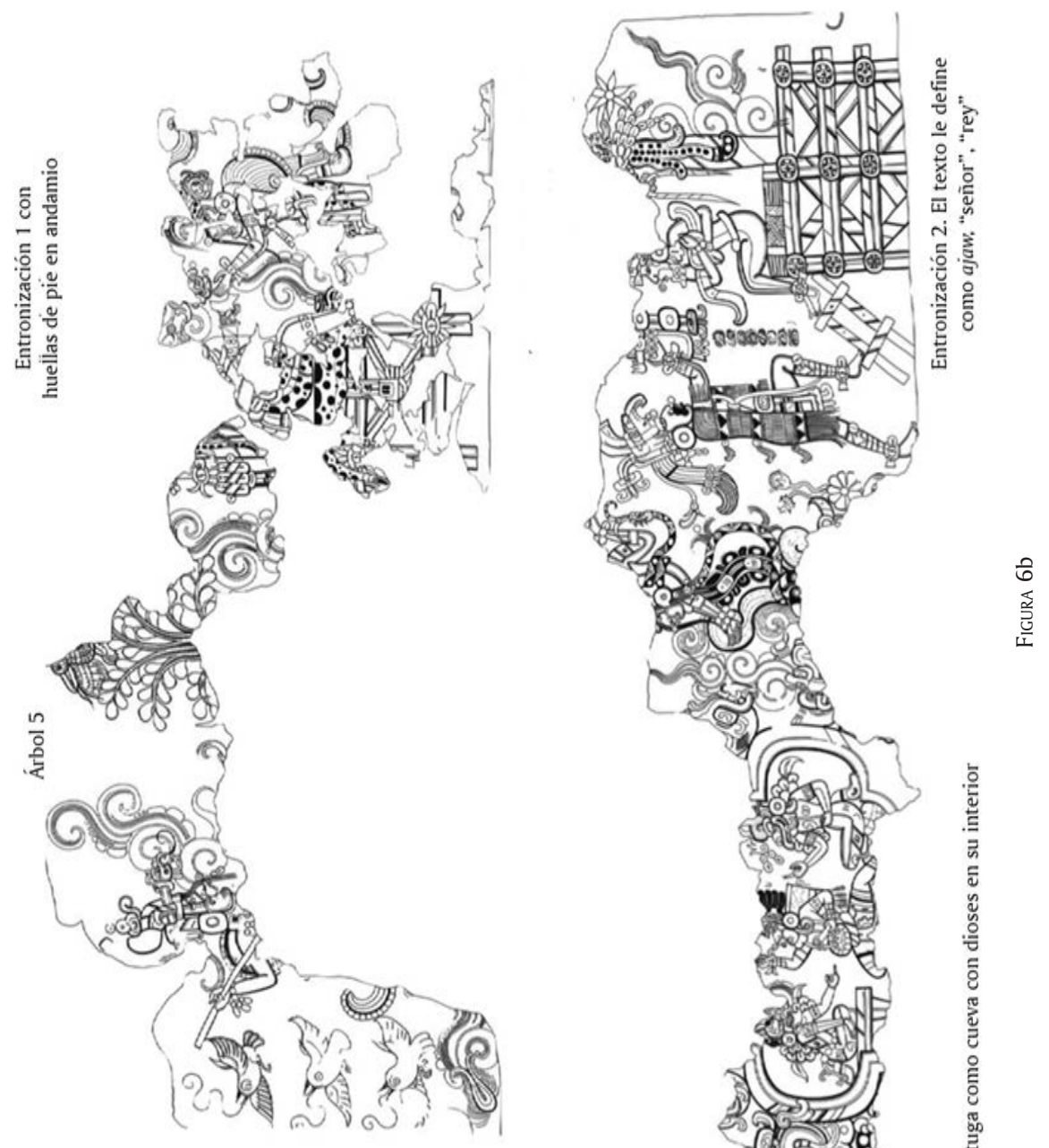
Bajo este Lagarto Celeste, con la Deidad Pájaro Principal que inunda la tierra con su lluvia, se advierte el siguiente episodio del mito: la creación de los cinco árboles direccionales sobre los que se posa el Pájaro Principal (Taube et al., 2010: 29-46).

Como apuntan Taube et al., en este mural los cuatro personajes que se sangran ante los árboles son una forma preclásica de Jun Ajaw, el correspondiente clásico del héroe gemelo del Popol Vuh, Junajpu (2010: 18-19). Parece que estos individuos estarían en relación con los "Cuatro Señores" mencionados en el Clásico y que serían los responsables de fundar el mundo y su centro, dándole orden. Los autores los asocian también con finales de periodo, con ritos de naturaleza calendárica, y serían los equivalentes de los cargadores de año, como los que aparecen en el Códice de Dresde y en otros contextos posclásicos mesoamericanos. Estos cargadores están vinculados con los rumbos y van alternándose. En el manuscrito de Dresde, de las páginas 25 a 28 estos cargadores se muestran justo después de la página 74, que recoge la escena del dragón celeste inundando la tierra. Las páginas siguientes del manuscrito, 30 y 31, están dedicadas a los cuatro árboles del mundo, el centro está marcado por una cueva, en todos ellos también se encuentra Chaahk, al igual que en otros monumentos preclásicos, donde siempre aparece en cuevas (García Barrios, 2007), y en el Clásico en la vasija K609, también conocida como Plato Cósmico, es el dios del Rayo que renace como Chak Xib' Chaahk de la aguada negra o gran inundación (figura 7) (ver Schele y Miller, 1986; Wagner 2001: 287; Velásquez, 2007: 2; Velásquez, 2002b: 442-443; García Barrios, 2009: 287-290).

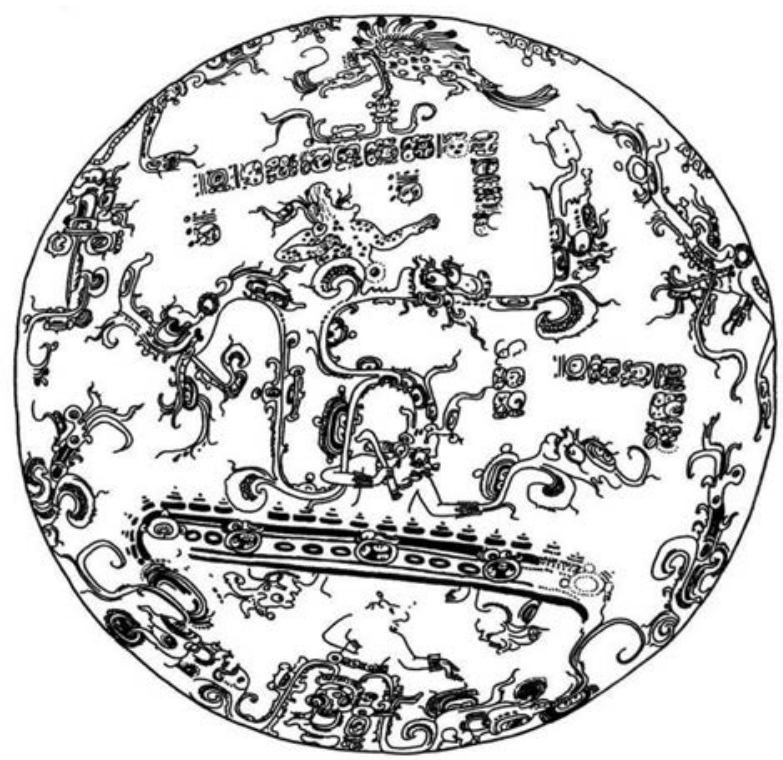

Figura 7. Vasija K609 o Plato Cósmico, periodo Clásico 
En los murales de San Bartolo, frente al quinto árbol se encuentra el dios del maíz, tal vez aludiendo a la planta del cereal como centro del mundo (Taube et al., 2010: 61). El último pasaje gira en torno a una cueva (ver figura 6b) donde se encuentran tres deidades y, a cada lado, dos figuras sentadas en tronos (Taube et al., 2010: 61, 66-69). En el lado sur del muro (izquierda de la cueva) hay un señor sentado sobre andamios, con otro frente a él, entronizándole. Ambos son prefiguraciones del dios del maíz. En el andamio del que se está coronando se advierten huellas de pies, que, como acertadamente indican Taube et al. (ibid.), se encuentran en ocasiones también en el Clásico en escenas de entronización relacionadas con sacrificio, aunque en este caso concreto no están asociadas con sacrificio alguno. Esto probablemente se debe a que estas huellas aluden a la acción de pisar en el sentido de fundar el nuevo mundo como metáfora visual de la creación de un nuevo reinado.

A esta escena le sigue un personaje que porta en brazos al dios del maíz niño caminando por una corriente de agua que termina en una cueva-montaña con forma de caparazón de tortuga, cuadrilobular, que es la manera de representar la montaña-cueva que simboliza el centro del mundo. En los rituales de fundación, el centro del espacio debe estar formado por una montaña-cueva con manantial y agua, tal y como se reproduce aquí (Taube et al., 2010: 73). Ambas entronizaciones giran en torno a esa montaña-cueva, en cuyo interior se encuentran varios dioses, ${ }^{12}$ entre ellos, Chaahk, el dios del maíz, tocando el tambor en el centro, y, al otro lado, el dios del agua terrestre (García Barrios, 2007; Taube et al., 2010: 73-75). La narrativa del muro poniente de San Bartolo finaliza con la entrega de los atributos de poder al otro personaje que se está entronizando, flanqueando el lado izquierdo de la cueva. También está sentado sobre un andamio, y en este caso el texto le designa ajaw (Taube et al., 2010: 68-70).

Resumiendo, en este espacio parece que se plasmó el mito completo de la inundación, destrucción por un diluvio y creación del mundo por la erección de cuatro árboles para recrear el tiempo que comenzaba con la entronización del nuevo gobernante, tal y como fue costumbre mostrar en el periodo Clásico.

\section{Huellas de pie y entronizaciones en el periodo Clásico}

Durante el Clásico, el reptil de la inundación formó parte de los programas iconográficos que mostraron los soberanos de las ciudades políticamente más relevantes del momento: Copán, Quiriguá, Palenque, Piedras Negras y otros reinos mayas de las Tierras Bajas. Al igual que en el Altar 12 de Takalik Abaj, los gobernantes se mostraron en las estelas dominado y pisando a este lagarto, aunque de una manera diferente. Es probable que la simbología fuese la misma. Este ser celeste

\footnotetext{
12 Chaahk es uno de los tres dioses que están en el interior de la cueva, uno de los espacios que más habita. Además es una entidad que participa en los eventos relacionados con la inundación (García Barrios, 2009: 226-266).
} 
y ambivalente por su dualidad (al ser causante de la inundación de la tierra, así como el responsable de que se forme y cree el nuevo mundo, partiendo de su cuerpo decapitado y caído), fue reproducido decorando palacios o estancias especiales.

También se representó este tema en la cerámica clásica, donde la forma de expresar el mito varía. Los maestros de las vasijas estilo códice, aquellos que delineaban en las piezas sólo los contornos de las figuras, recrearon el mito en soportes elegidos intencionalmente, como son platos y vasijas de base cuadrangular, pero a diferencia de como suele ocurrir en los monumentos de piedra, donde los protagonistas son los soberanos, aquí, los protagonistas son entidades sagradas. Los dioses se vinculan en diferentes momentos del mito con el lagarto celeste, entre ellos Chaahk, el dios L, y el dios del maíz. El dios G III también, pero en este caso fue modelado en barro encima del cocodrilo, como se explica más abajo.

\section{El Clásico Temprano: Cocodrilo Venado Estelar y huellas de pie}

\section{La Estructura Margarita de Copán}

La Estructura Margarita de Copán (Honduras) (ver figura 2) es el primer monumento del periodo Clásico donde se muestran huellas de pie en un contexto compartido con el Cocodrilo Venado Estelar, no sin olvidar, como se ha dicho antes, que ya en el Preclásico Tardío se encuentran en los murales de San Bartolo huellas de pie en una narrativa más extensa de la inundación.

La ciudad de Copán fue fundada en el año 426 d.C. por un extranjero de gustos teotihuacanos llamado K'inich Yax K'uk' Mo'. ${ }^{13}$ Los registros arqueológicos y los análisis de dientes del rey señalan que su procedencia es foránea. Esto, unido a los materiales de diseños teotihuacanos encontrados en sus edificios, hizo pensar a los investigadores que se trataba de un personaje procedente del centro de México (Sharer, 2003: 145). En la actualidad sabemos que K'inich Yax K'uk' Mo' pasó su infancia en Petén y luego se desplazó al valle de Copán (Price et al., 2014), donde fundó la dinastía que regiría el sitio hasta el final de su historia. ${ }^{14}$ Pese a que su infancia transcurrió en algún lugar del Petén, K’inich Yax K’uk' Mo'

\footnotetext{
${ }^{13}$ Sus retratos lo vinculan con los dioses teotihuacanos, pues suele mostrarse con la anteojeras de Tláloc, dios de la lluvia y el rayo de esa cultura. Los ajuares de los entierros asociados a este primer momento muestran objetos puramente teotihuacanos, como son los espejos de pirita, vasijas anaranjado delgado, anteojeras de concha y tocados de placas de concha. Igualmente, las primeras obras arquitectónicas patrocinadas por este gobernante presentaban los diseños típicos de la arquitectura teotihuacana conocidos como estilo talud-tablero, señalando un fuerte vínculo o atracción con esa poderosa ciudad del centro de México (Fash, 2002: 717-18).

14 Algunos autores sugieren que el fundador procede de la región de Petén, Tikal o de Caracol (Stuart, 2000, 2008; Lacadena y Ciudad, 2009: 61; Price et al., 2014).
} 
siempre mostró preferencias y gustos teotihuacanos, tal vez por las tendencias regionales del momento. Esto se advierte en el diseño arquitectónico de los edificios que patrocinó ${ }^{15}$ y en la cantidad de objetos teotihuacanos con los que se le enterró (Sharer, 2003: 148-151).

Con la muerte del fundador sube al trono K'inich Popol Hol, al que se le atribuye la construcción de la Estructura Margarita, entre los años 445 y 460 d.C. (Sharer, 2003: 152-153). Según los arqueólogos del Proyecto Copán (Sharer, ibid.; Fash, 2002: 715-729), este edificio estuvo destinado a guardar el cuerpo de la mujer del fundador. La fachada oeste de la estructura, al igual que los edificios patrocinados por K'inich Yax K'uk' Mo', presentan una mezcla de motivos mayas y teotihuacanos. Si el espectador se fija, observará que la composición de la fachada sigue un patrón de diseño teotihuacano; ${ }^{16}$ un paramento central, un marco inferior y otro marco que bordea por tres de sus lados la escena central. En el espacio del centro se modelaron dos aves (guacamayo y quetzal) con los cuellos entrelazados, que representan el nombre en emblema del gobernante K'inich Yax K'uk' Mo', “Solar primer quetzal guacamayo”. Esa forma de representar un nombre en emblema era algo poco usual en el área maya, y recuerda más a diseños teotihuacanos (Martin y Grube, 2002: 192; Nielsen, 2003: 227). El nombre en emblema va acompañado de un texto glífico formado por el numeral 9, tal vez en el sentido maya de "mucho o innumerable", o, como argumenta Nielsen (2003: 228), con el de "nueve sitio", un lugar del imaginario mítico. Le sigue un glifo no descifrado y otro formado por dos huellas de pies. El marco inferior cierra con una banda formada por signos terrestres. La moldura superior y los laterales, que son en realidad el cuerpo del Cocodrilo Venado Estelar, encuadran el nombre en emblema del gobernante. La cabeza delantera del lagarto cuelga por uno de los laterales del marco, y la cabeza trasera, por el otro. En la parte superior figura el cuerpo del lagarto adornado con los signos celestes. Esta manera de enmarcar copia los patrones teotihuacanos, cuando representan a la Serpiente Emplumada anegando la tierra con su torrente de agua.

La cabeza delantera del Cocodrilo Venado Estelar lleva un ojo con signo de estrella, mientras que la posterior es una cabeza descarnada. Este ser arroja por su hocico largo y abierto, con dientes curvos, un caudaloso torrente de agua que arrastra un conjunto de objetos que Velásquez (2002a: 240; 2007: 2) ha identificado como conchas, cuentas de jade, huesos pequeños, hileras de pun-

\footnotetext{
${ }^{15}$ Uno de los edificios que mandó construir fue Hunal, que en principio debió tener función de palacio y después de su muerte se convirtió en tumba real (Sharer, 2003: 147-151). Pese a ser una subestructura y haber sido en parte destruida, su interior conserva diseños de pintura mural de estilo teotihuacano, y se advierten los recursos de huellas de pies, tan característicos del lenguaje visual en Teotihuacan (Sharer et al., 1999: 241; Nielsen, 2003: 223).

${ }^{16}$ Las pinturas murales en los paramentos de los edificios teotihuacanos suelen presentar siempre un mismo patrón: en la parte central se ubica el tema principal, en la baja una banda que hace de locativo, es decir indica dónde acontece la acción, y un marco de tres lados en la parte superior, cuya temática está siempre en relación con la escena central (Lombardo, 2006:36). Este diseño tan peculiar fue el elegido para recrear un acontecimiento político de gran relevancia en la estructura Margarita.
} 
tos, signos de completamiento y logogramas de K'AN y YAX, asociados con la lluvia torrencial o con la inundación. ${ }^{17}$ Abrazado a la cabeza trasera y descarnada se encuentra, blandiendo su hacha, el dios de la lluvia, Chaahk, probablemente con la intención de dar muerte al caimán (García Barrios, 2009: 161-173), y así enfatizar el fin del tiempo anterior, simbolizado por la muerte del cocodrilo, y la restauración de un nuevo orden marcado por las huellas de pies y la presencia del gobernante a través de su nombre en emblema. Parece que la llegada de un personaje foráneo a la ciudad de Copán para fundar un nuevo reino pudo ser el motivo último de esta representación.

Muchos de estos elementos iconográficos serán utilizados en los siglos venideros en ciudades de la región del río Usumacinta, siendo Piedras Negras uno de los reinos del Clásico Tardío con más monumentos en piedra que muestran al soberano ataviado a la manera teotihuacana, sentado sobre el Cocodrilo Venado Estelar, y con unas huellas de pies que ascienden hacía el personaje entronizado.

\section{Monumentos del Clásico Tardío: entronización, Cocodrilo Venado Estelar y huellas de pies}

Durante el Clásico Tardío la presencia del rey entronizado sobre el Cocodrilo Venado Estelar y unido a un camino de huellas de pies se generaliza en la ciudad de Piedras Negras. Igualmente, los reyes de Palenque diseñan y se vinculan a dicho ser en diferentes monumentos, así como recrean parte del mito al mencionar la decapitación del reptil en el texto de la Plataforma Jeroglífica del Templo XIX de Palenque (Stuart, 2000, 2005; Velásquez, 2002b, 2007). También en zonas alejadas del Usumacinta, como Naranjo, en Petén, en este momento los gobernantes se retratan sentados sobre el Cocodrilo Venado Estelar, o en la misma ciudad de Copán, que nunca dejó de diseñar a este lagarto en altares, zoomorfos y otros monumentos.

\section{Piedras Negras}

Piedras Negras es, como se señaló antes, una de las ciudades del Clásico Tardío con mayor número de monumentos conteniendo el patrón gobernante, Cocodrilo Venado Estelar y huellas de pies. Se puede ver este diseño en las estelas 6, $11,14,25$ y 33. La primera que se realizó, la 25 (figura 8), fue encargada por el rey K'ihnich Yo'nal Ahk I (608 d.C.) y sus sucesores copiaron el patrón. Martin y Grube (2002: 142-143) consideran que estas estelas muestran al rey entronizado sentado en un palanquín o litera muy decorada, elevada simbólicamente al reino de los cielos. Un cojín de piel de jaguar que conforma su trono reposa sobre una

\footnotetext{
${ }^{17}$ Elementos semejantes a éstos se advierten en los fluidos teotihuacanos que descargan la Gran Diosa, Tláloc y otros muchos personajes. Corona Sánchez (2002: 380) argumenta que son productos relacionados con la economía teotihuacana: semillas, conchas, caracoles y productos manufacturados, que coinciden más con la descripción que hace el Chilam Balam.
} 


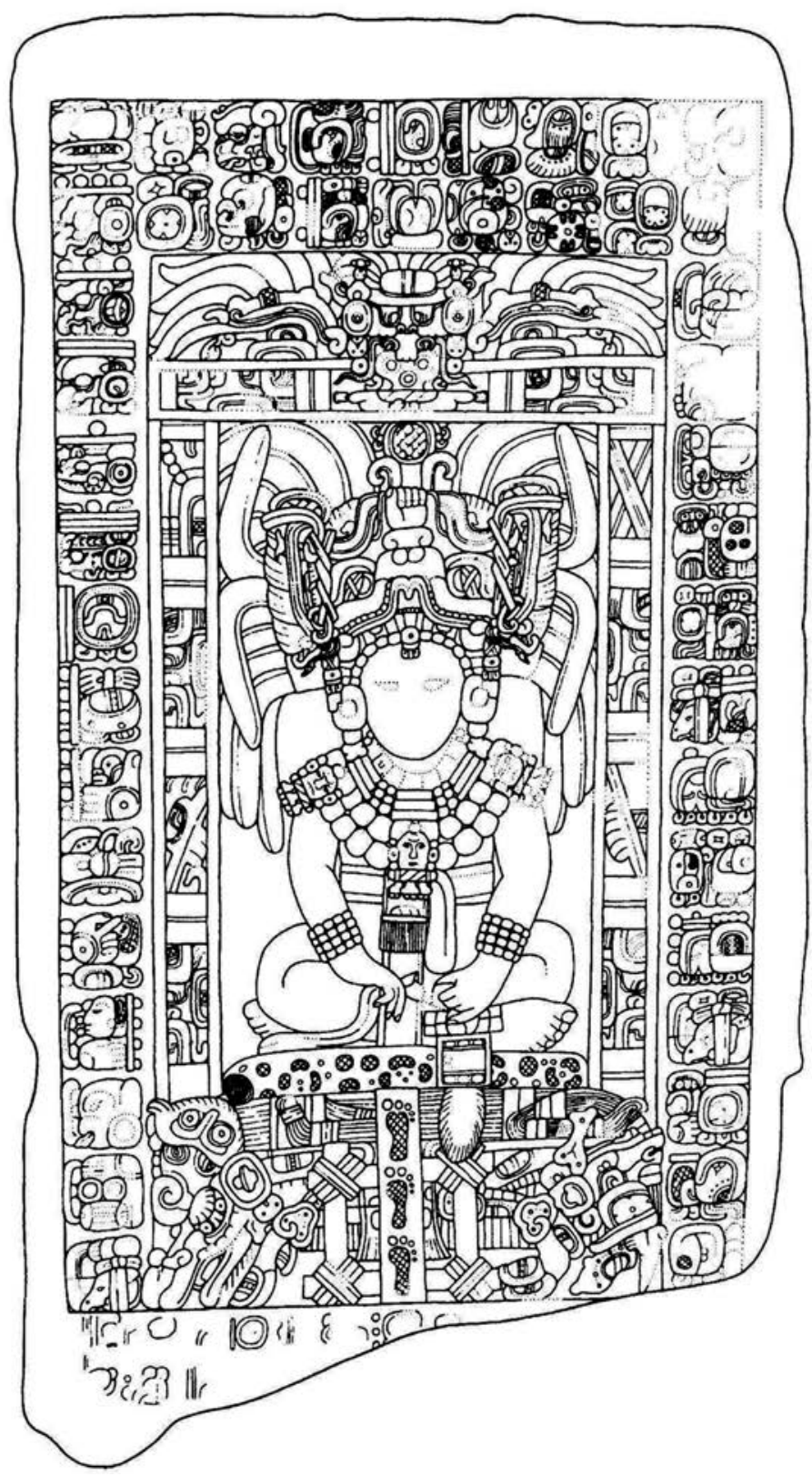

Figura 8. Estela 25 de Piedras Negras, Clásico Tardío 
efigie de bejuco con forma de saurio; todo ello bajo un dosel que representa el cielo, coronado por el gran pájaro celestial. El reptil de bejuco es en realidad el Cocodrilo Venado Estelar, atado y sometido. También en un fragmento de una vasija clásica se reconoce este mismo tema: el gobernante, sentado en lo alto de un andamio, está siendo investido con el tocado real. Formando parte del andamiaje se encuentra, atrapado y atado, el cocodrilo de la inundación, siguiendo el mismo patrón que se advierte en las estelas clásicas (Taube et al., 2010: 64, figura 41b). Una situación que se asemeja mucho a la que se reproduce en las páginas 3, 5, 9 y 11 del Códice París, donde se observa a un gobernante en el momento en que recibe los emblemas reales, sentado sobre el cocodrilo de la inundación, atado (Love, 1994). La posición del rey no es casual, sino una forma de mostrar que tiene bajo su control al agente encargado de destruir el mundo. Es el gobernante responsable de la muerte del reptil.

En las estelas de Piedras Negras suelen incluirse huellas de pies que ascienden pisando el cuerpo del lagarto desde los signos terrestres de la parte inferior de los andamios hasta el trono donde se encuentra sentado el señor (Velásquez, 2007: 4; Taube, 1988: 340-350). Martin y Grube (2002: 142) sugieren que se trata de huellas de pies ensangrentados del gobernante, producto del sacrificio de una víctima. Pese a que era práctica generalizada el sacrificio humano en ocasión de subir al trono o en fechas relevantes, pienso que aquí esas huellas de pie aludirían a la acción de pisar como sinónimo de la fundación del nuevo reino que iba a dar comienzo. Tal y como se ha dicho, en la entronización preclásica del mural poniente de San Bartolo no se muestra cautivo alguno, y aunque tampoco está el reptil atado y controlado por el soberano, se encuentra igualmente asociado a él en el discurso general del mural.

El Cocodrilo atado se identifica también en los rituales de fundación recogidos en la Colonia, como se explica en el apartado siguiente. La acción de pisar es imprescindible en las fundaciones, ya sea de reinados, señoríos o nuevos periodos de tiempo.

\section{Naranjo}

La estela 32 de la ciudad de Naranjo (figura 9) muestra elementos semejantes a los de Piedras Negras y otros diversos, pero sumamente interesantes por las vinculaciones que pueden tener con el centro de México. El gobernante está sentado sobre una elevada escalinata, tal vez una pirámide, decorada con signos celestes y terrestres que rematan en la parte superior con la figura de un ser serpentino, con cuerpo alargado, emplumado y con patas de venado, atado y amordazado.

Existen otras representaciones de este cocodrilo con el cuerpo emplumado, como se ve en el Altar T de Copán, posiblemente por la fuerte tradición teotihuacana que siempre existió en esa ciudad. En este caso debemos preguntarnos ies acaso la Serpiente Emplumada la equivalente en el centro de México al Cocodrilo Venado Estelar del área maya? Podría ser, pues siempre aparece anegando la 


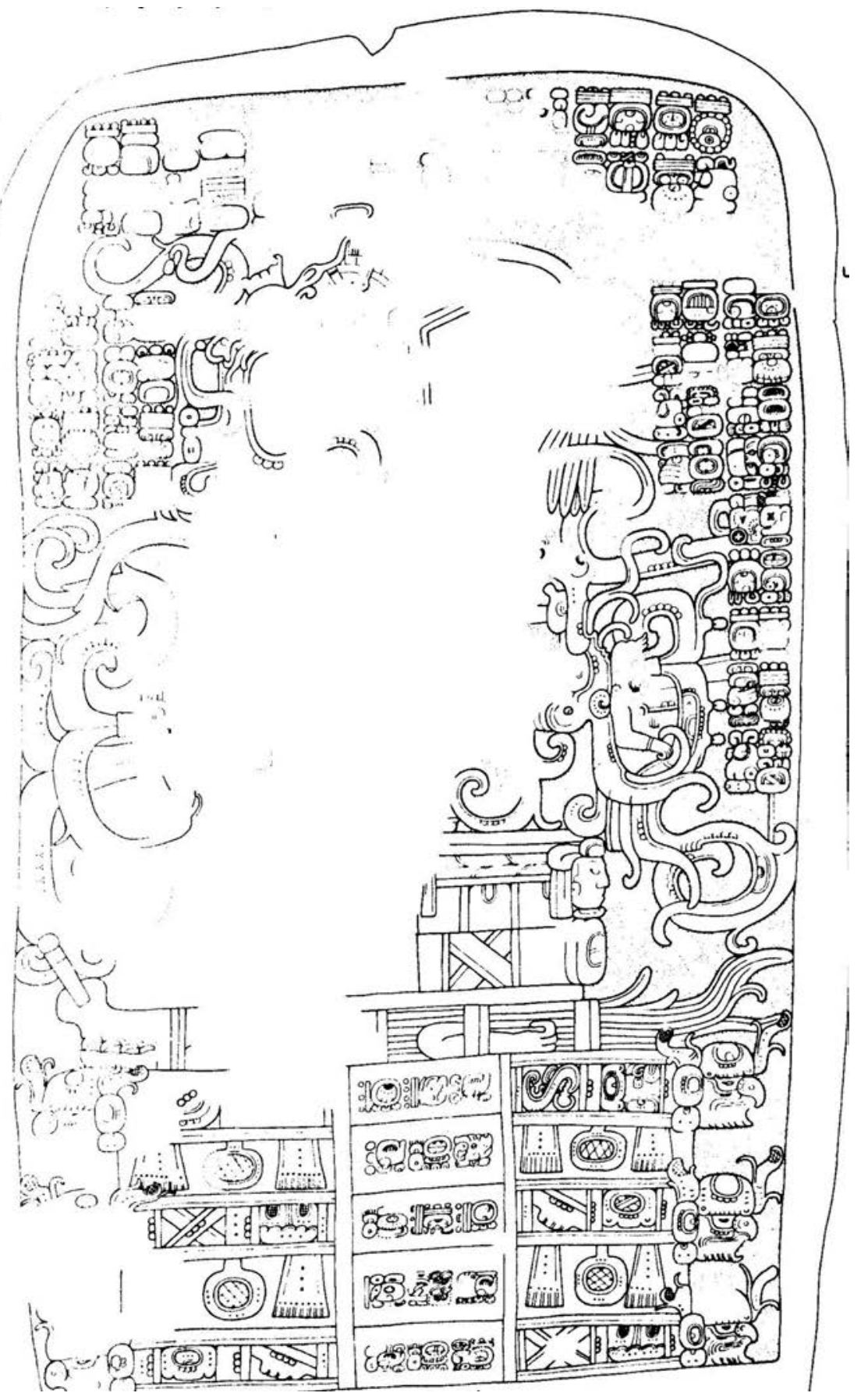

FIgURA 9. Estela 32 de Naranjo, Clásico Tardío 
tierra con un potente fluido saliendo de su boca. En ocasiones, bajo su cuerpo se advierten nueve árboles, en lugar de cuatro, tal vez con el mismo significado que tenían en el área maya: la restauración del mundo. Además, el Templo de la Serpiente Emplumada es el escenario perfecto para mostrar iconográficamente en sus fachadas a este ser híbrido, reptil y ave, en un entorno acuático marcado por caracolas y otros elementos, los mismos que se encuentran en los múltiples entierros de sacrificados que se produjeron en esa pirámide.

Ciertas representaciones teotihuacanas, como las que figuran en el Mural de los Animales Mitológicos, muestran al ofidio en un contexto acuático acompañado de diferentes animales, vomitando fluidos e ingiriendo animales. Su cuerpo emplumado y blanco parece entrar y salir del agua mientras arroja cantidades de líquido por la boca. A veces da la sensación de que su cuerpo, más que invisible, porque penetra en el interior del agua (indicada por olas que lo cubren a tramos), estuviese seccionado o cortado. Según algunos autores (Sugiyama, 1992; López Austin et al., 1991; Florescano, 2009), la Serpiente Emplumada en el centro de México ejerce como emblema fundacional. Son muchas las representaciones de dignatarios asentados sobre el cuerpo de la serpiente como símbolo de la autoridad política y de la casa real de Teotihuacan. Tal vez, el Cocodrilo Venado Estelar con plumas que aparece en Naranjo, ese animal híbrido que es mencionado en el Chilam Balam de Chumayel (Mediz Bolio, 2001: 88) como la Serpiente de Vida, a la que le robaron los cascabeles de su cola y sus plumas de quetzal, sea una fusión de los monstruos de la inundación del centro de México y del área maya. En cualquier caso, el significado último de esta imagen sería el mismo: transmitir el control y poder del rey como regente del orden cósmico a su pueblo.

\section{Huellas de pie en los monumentos posclásicos}

Como apunta Taube (2010: 204), este episodio también se describió durante el Posclásico en los murales de Mayapán, donde aparece el cocodrilo atado en un contexto acuático junto con otros animales. Este cocodrilo podría ser el mismo que aparece en la Estela 1 de Mayapán, cuya escena muestra al gobernante sentado sobre el lagarto con un sacerdote portando emblemas de poder y ritual, como incensarios, y además también está el Pájaro Principal, entidad sobrenatural que desde el Preclásico Tardío aparece en la iconografía del mito. Todo ello coincide con las imágenes reproducidas en las primeras páginas del Códice París (Love, 1994). También los códices Dresde y Madrid reproducen escenas relativas al monstruo de la inundación, como la conocida imagen de la página 74 del Códice Dresde (figura 10). El reptil con el cuerpo formado por signos celestes, se dobla para vomitar una corriente de líquido que emana de su boca pero también de su cuerpo, como en San Bartolo. Aquí, la vieja diosa Chak Chel ayuda a anegar la tierra con un cántaro invertido sobre el anciano Dios L, identificable por su tocado de pájaro moan aunque aparezca blandiendo armas y con el cuerpo pintado de negro. 


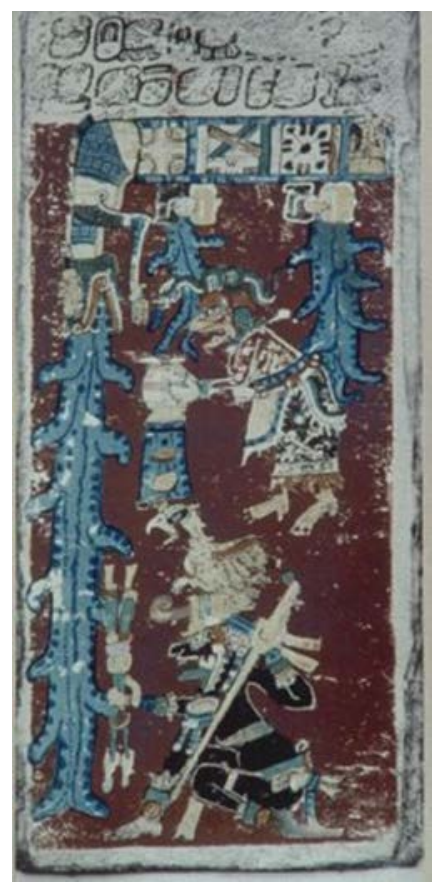

Figura 10. Página 74 del Códice Dresde

En las Relaciones Histórico-Geográficas de la Gobernación de Yucatán, del siglo xvI (apud De la Garza et al., 2008, I: 43-86), se menciona que hacían un cocodrilo con varas atadas, que luego quemaban en señal de que el mundo anterior había acabado por un diluvio. Muy probablemente un lagarto atado similar a los que se muestran en Piedras Negras, Naranjo, Mayapán o el Códice París.

También es interesante la glosa que aparece escrita en el pasaje que alude a la decapitación del Cocodrilo Venado Estelar de la Plataforma Jeroglífica del Templo XIX de Palenque (ver figura 3), que asienta: "la persona que taladra el fuego", seguido de la expresión "y entonces fue formado", interpretado como una referencia a la creación del nuevo orden cosmológico (Stuart, 2005: 76; Velásquez, 2007: 4). Los rituales de fuego nuevo, que tanta tradición tienen en el centro de México, también se advierten en el área maya desde al menos el Clásico Temprano, coincidiendo con el momento de relaciones con Teotihuacan (Guenter, 2002: 26; Nielsen, 2003: 90; Valencia y García Barrios, 2009: 85-96). Igualmente, los mayas del Posclásico emplearon este ritual para festejar las ceremonias de Año Nuevo, como se observa en el Códice Dresde.

Durante la Colonia, las ceremonias de fundación descritas por García Zambrano (1994: 221) y Smith (2006: 268) finalizaban con una hoguera en el centro para sacralizar el espacio, concepto que inevitablemente lleva a pensar en los rituales que estamos mencionando. 
Hay diferentes evidencias en los títulos de tierras recogidos durante los primeros años de la Colonia que señalan que el acto de pisar es imprescindible en los rituales fundacionales mesoamericanos. Reproducían el paso del tiempo como un recorrido hecho a pie, patrón bastante generalizado en Mesoamérica. García Zambrano (id.; Scandar, 2010: 68), al describir el Mapa de San Mateo Ixtlahuacán, de 1530 (figura 11a), apunta que estas ceremonias constaban de varias etapas. Comenzaban con el sonido de instrumentos musicales, que ejercían de pregón en el rito de demarcación de lindes de tierras. Interesantemente, a continuación, se elegía una montaña con cueva y un pozo de agua cercano, que sería el centro del territorio, idea que concuerda con el concepto de Chicomoztoc tan difundido en Mesoamérica, acaso representada en los monumentos clásicos como los escalones que simbolizan la pirámide sobre la que se muestra el gobernante. Esta montaña será el punto de partida y de llegada de la procesión que recorrerá pisando su perímetro e interior. A continuación, estas demarcaciones eran delimitadas usando cuerdas y o ramas atadas

[...] Luego, eran colocados a lo largo de la línea divisoria marcadores de piedras o estelas para proveerlo de un registro visual y simbólico [...]. La procesión sale del

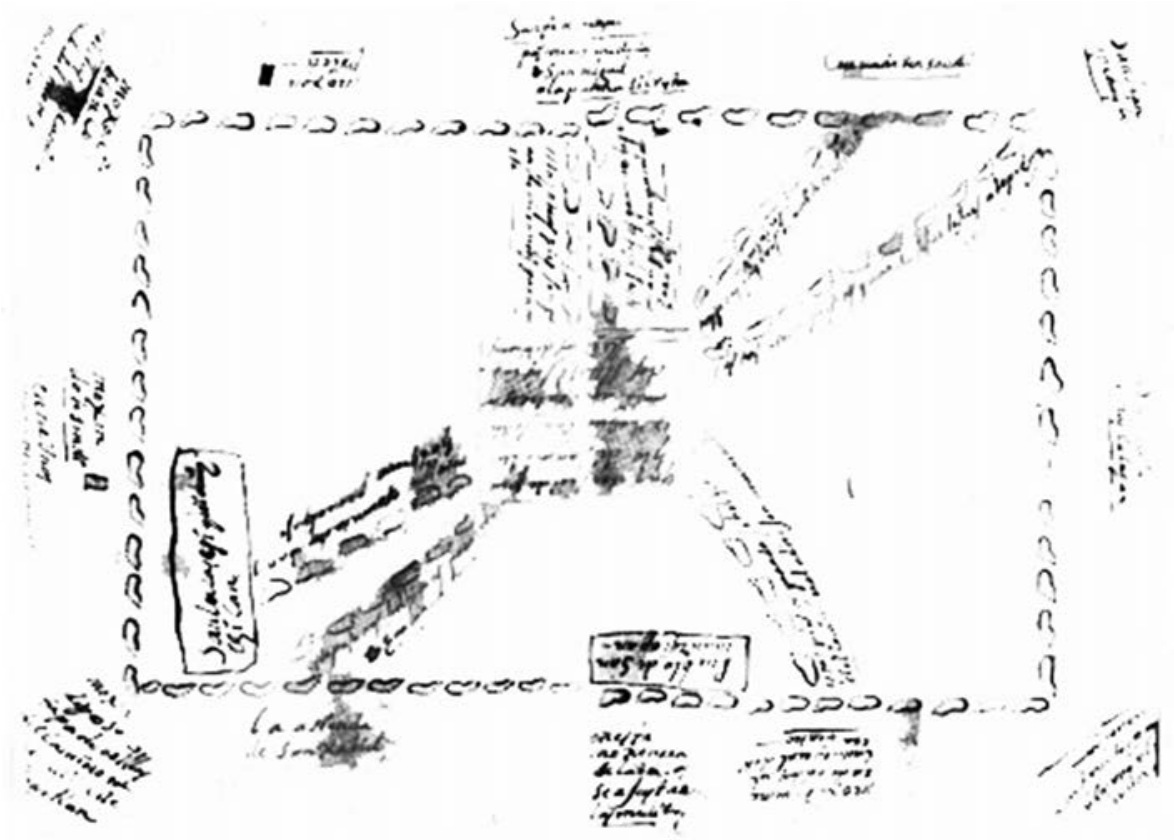

Figura 11a. Mapa de San Mateo Ixtlahuacán, 1530 
centro y camina hacía el norte, luego el grupo continua caminando hacia el oeste, después hacía el sur y encontrando el este volvían al punto de partida, al centro. A esto seguía un banquete ritual a los pies de la montaña central [...] tras lo cual la procesión volvía a subir. Una vez arriba, se realizaba una serie de ceremonias adicionales: la quema del círculo de ramas y el disparo de flechas hacia los cuatro puntos cardinales [...], para finalizar con la organización de los cuatro barrios en cada rumbo (García Zambrano, id.).

Las diferentes ceremonias celebradas en este ritual maya colonial coinciden en su totalidad con los rituales de fundación de ciudades del centro de México, tal y como recoge Smith al describir las páginas de fundación de la Historia Tolteca-Chichimeca (2006: 266-268). En ambos ejemplos se reconocen huellas de pies señalando el camino recorrido. No parece casual que el desplazamiento de la procesión salga del centro, se desplace al norte, luego al oeste, continúe al sur, y por último al este, de donde se regresaba al centro, en el sentido contrario a las agujas del reloj. El mismo recorrido que la ordenación de los árboles que sustentaron el cielo después de la inundación descrita en el Chilam Balam: el primer árbol que se levantó fue al norte, después el del oeste, el siguiente fue el del sur. Prácticamente igual que el orden que siguen los cuatro árboles en las páginas 30 y 31 del Códice Dresde. Podríamos decir entonces que en los rituales de fundación es fundamental repetir los patrones diseñados por los dioses cuando ordenaron la Tierra, norte, oeste, sur, este, y se finaliza en el centro. Como señaló Paxton (2009: 284) la dirección del recorrido en el sentido contrario al de las agujas del reloj está en relación con el camino diario del sol y con el origen del tiempo, pues hay fuentes que señalan la representación del paso del tiempo como un recorrido hecho a pie.

Esta idea de fundar las ciudades recreando los patrones estipulados por los dioses, dividiendo la tierra en cuatro secciones, quedó recogida en el mapa de Yucatán que dibujaron los escribas del Chilam Balam de Chumayel: un círculo dividido en cuatro secciones, con el centro señalado por un círculo menor (ver Roys, 2008: 73).

Esta creencia sobre cómo debía ordenarse el mundo se mantiene entre los mayas actuales. Girard (1962: 43) narra que en sus rituales los chortí siguen la descripción del Popol Vuh acerca del modo en que se acabó de formar todo en el cielo y la tierra "cómo fue formado y repartido en cuatro partes, cómo fue señalado y el cielo fue medido y se trajo la cuerda de medir y fue extendida en los cuatro ángulos, en los cuatro rincones". ${ }^{18}$ El sentido de pisar podría ser el mismo que el

${ }^{18}$ De forma muy visual se aprecia esta misma idea cuatripartita del espacio, aunque sin huellas, en la primera página del Códice Mendoza. El centro lo compone el águila sobre el nopal comiendo la serpiente, el símbolo que los dioses indicaron a los aztecas que debían reconocer para asentarse en su nueva tierra. Esta página del códice queda dividida en cuatro secciones y en cada una de ellas se encuentran los señores con sus nombre y árboles asociados a cada uno de su señoríos que tal vez representen el territorio de cada uno en sí mismo, de la misma manera que ocurre en el Códice de Madrid. Cabe recordar que en el documento estudiado por García Zambrano, tras finalizar la ceremonia el territorio se dividía en cuatro cuadrantes o barrios (apud Scandar, 2010: 68). 
descrito en el Popol Vuh con la expresión "cómo fue señalado". Estas acciones de pisar para fundar un nuevo territorio encajan con la idea dibujada en las páginas 75 y 76 del Códice Madrid ${ }^{19}$ (figura 11b), donde las huellas marcan las direcciones asociadas a los cuatro puntos cardinales. Igualmente, es posible que este mismo concepto sea el que se represente también en la página 39 del Códice Borgia y en las anteriores a ésta, donde se registran las huellas que va dejando un grupo de señores que recorren el espacio central formado por una montaña-cueva. ${ }^{20}$

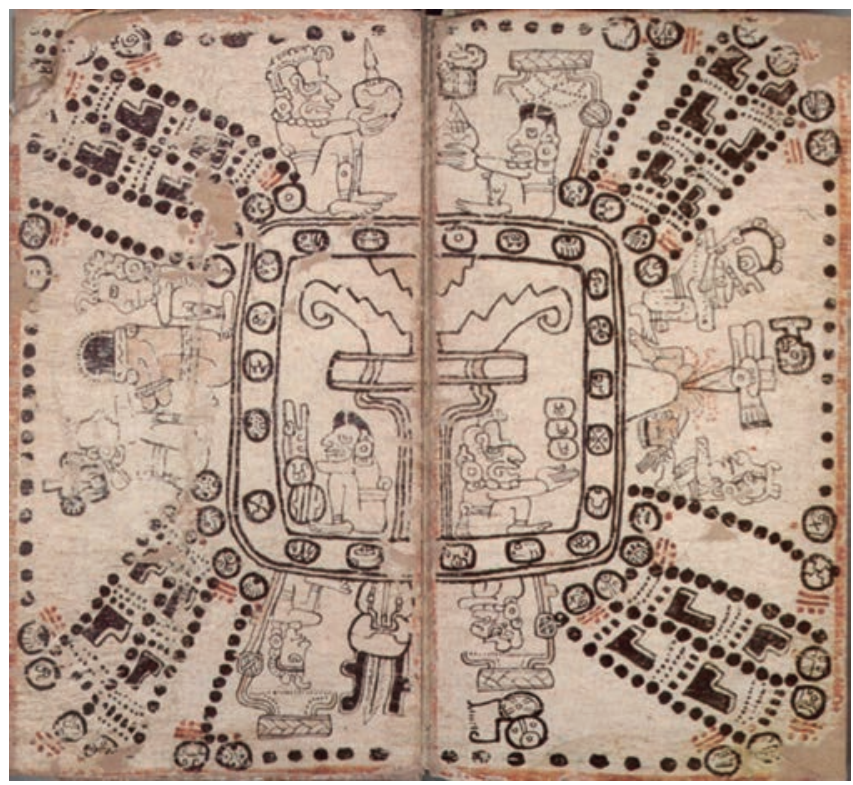

Figura 11b. Páginas 75 y 76 del Códice Madrid

Estos datos sugieren que la intención última de los escultores mayas al reproducir huellas de pies en algunos de los monumentos clásicos donde se representó el Cocodrilo Venado Estelar pudo ser señalar el acto de pisar cómo metáfora visual que reproducía el ordenamiento del mundo.

${ }^{19}$ Aunque sin registro de pisadas, el esquema cuatripartito que rige las cuatro direcciones y marcan los lindes con cuatro árboles en estos eventos de fundación puede ser el que quedó recogido en la primera página del manuscrito prehispánico del centro de México conocido como Tonalamatl de los Pochtecas o Códice Fejérváry-Mayer. Cómo argumenta León Portilla (2005: 18), esta primera página presenta una imagen horizontal del universo con los cargadores de cada año marcando los cuatro rumbos y a la vez indicados con árboles asociados a los sectores que delimitan y marcan el mundo.

${ }^{20}$ En este sentido, también llama la atención la importancia que refleja el espacio montaña-cueva donde habita el dios de los aztecas, Huitzilopochtli, según se ve en La Tira de la Peregrinación. Los aztecas peregrinan para dejar ramas de abeto, tal y como se expresa que ocurre en el documento colonial de fundación. Sin duda este manuscrito muestra, desde la perspectiva del siglo xvi, la idea del lugar de origen fundado en un tiempo anterior, cuyo centro rector es la montaña-cueva donde habita el dios tutelar. 
Tatiana Proskouriakoff (1960: 455) advirtió que en las estelas de Piedras Negras se presenta la ceremonia de entronización de los reyes como un acto de relevancia cósmica. La idea es muy acertada, ya que el Cocodrilo celeste simboliza el caos, y el gobernante al pisarlo le vence, creando y ordenando el nuevo tiempo, el tiempo de su reinado. Por tanto, se puede decir que en todos los monumentos expuestos antes, el lagarto es una metáfora visual de la destrucción de un tiempo anterior expresado por el Cocodrilo Venado Estelar, y a la vez la creación de un nuevo tiempo y orden representado por las pisadas ascendentes como acto de fundación del nuevo reinado, cuyo garante será el nuevo rey.

\section{Conclusiones}

En este trabajo se ha defendido, siguiendo la propuesta de Scandar (2010), que la acción de pisar la espalda del lagarto descrita en el Chilam Balam no refleja una cópula como se había mantenido, sino estrictamente al acto de pisar, tal y como se hacía en los rituales de fundación de la época colonial. Esta propuesta da sentido a las imágenes clásicas de las estelas que muestran al gobernante sentado sobre el Cocodrilo Venado Estelar atado y unas huellas de pies ascendentes, que antes habían sido interpretadas como huellas de sacrificio, lo cual tiene sentido pero unido al acto de pisar como acción de marcar el territorio y de fundar.

En los códices posclásicos y documentos coloniales la fundación de una ciudad debía estar marcada por una serie de rituales, entre los que se incluía el desplazamiento señalado por las huellas de pies que marcaban las cuatro direcciones. Este recorrido se hacía en el sentido contrario a las agujas del reloj, en el mismo orden que se colocaron los árboles en las esquinas del mundo después de la inundación para restaurar el orden: norte, oeste, sur y oeste, para llegar al centro. Por eso, la acción de pisar se vuelve tan relevante en las estelas clásicas y en los documentos coloniales de fundación, era importante hollar la tierra, marcarla y ordenarla justamente igual que se ordenó el mundo en el tiempo mítico. De la misma manera los regentes mayas cada vez que subían al trono debían ordenar el mundo siguiendo este diseño aprendido de los dioses. Esto nos lleva a proponer que las huellas de pies son la forma gráfica de expresar la fundación de un nuevo reino, mediante la renovación y ordenación del nuevo tiempo. Un concepto que se advierte en los documentos prehispánicos, coloniales y actuales del centro de México y del área maya, donde el cocodrilo es la alegoría que simboliza la destrucción del tiempo anterior.

Igualmente, hay que resaltar que en el Mural Poniente de San Bartolo se muestran diferentes acontecimientos que parecen concordar con los datos aportados por los Chilam Balam y otros datos coloniales referentes a fundaciones. Recordemos que los elementos fundamentales para poder realizar los rituales de fundación eran una montaña-cueva con pozo de agua que ejercía de centro y de punto de partida en los recorridos que se realizan en estas ceremonias. Todas 
las secuencias del mito se hallarían representadas en las pinturas de San Bartolo: la inundación y la destrucción del mundo anterior indicado por la serpiente de doble cabeza derramando agua; la restauración del nuevo orden señalado por cinco árboles; la cueva-montaña y pozo de agua como centro del espacio fundacional, y el gobernante en el momento de la coronación. Si la descripción es correcta, estos murales muestran la narrativa más extensa y detallada de lo que sería la primera entronización conocida en el área maya asociada al mito de la inundación, como emblema de nuevo orden y fundación del reino.

Conviene añadir que durante el Clásico el cocodrilo no aparece decapitado. Tampoco parece que haya un único agente encargado de decapitar al saurio, como si los señores pudieran elegir los seres que se encargaban de dar muerte al cocodrilo. En este sentido, uno de ellos y el que más veces aparece representado desde el Preclásico hasta el Posclásico con el Cocodrilo Venado Estelar es Chaahk. Sin embargo, el texto de la Plataforma de Palenque parece señalar a GI como agente encargado de la ejecución de dicho cocodrilo. No es casualidad que el gobernante K'ihnich Ahku'l Mo' Naahb III se muestre el día de su coronación personificando al dios GI y ataviado con sus atributos. Esta concordancia entre rey y agente de la decapitación permite sugerir que la intención última de los gobernantes del Clásico, no sólo de Palenque sino de todas las ciudades donde incluyeron al saurio en los monumentos de acceso al trono, fue la de mostrarse ante su pueblo como héroes victoriosos que acaban con el caos del tiempo anterior al decapitar al cocodrilo, y como ordenadores y creadores del nuevo tiempo. GI es uno de los dioses principales de Palenque y por tanto parece lógico que en este caso sea él quien de muerte al caimán celeste, más que Chaahk o a GIII. Este último también aparece sentado sobre el reptil blandiendo un hacha, por lo que en algún momento pudo participar de alguna manera en este acto final de muerte.

Por último, cabe señalar que aquí se han apuntado sucintamente algunos datos que sugieren que la serpiente emplumada podría ser el equivalente del centro de México del Cocodrilo Estelar del área maya, una hipótesis sobre la que trabajo en este momento. 


\section{BIBLIOGRAFÍA}

Acuña, René (ed.)

1993 Vocabulario de Maya Than. México: Universidad Nacional Autónoma de México, Instituto de Investigaciones Filológicas, Centro de Estudios Mayas.

Anders, Ferdinand y H. Dekkert (eds.)

1975 Codex Dresdensis (Codex Dresden). Austria: Akademische Druck-u. Verlagsanstalt-Graz.

Barrera Vázquez, Alfredo (coord.)

1980 Diccionario maya-español/español-maya. México: Ediciones Cordemex.

Bernal, Guillermo y Erik Velásquez García

2005 "Manos y pies en la iconografía y la escritura de los antiguos mayas", Arqueología Mexicana, 71: 28-33.

Caso Andrade, Alfonso

2000 El Pueblo del Sol. México: Fondo de Cultura Económica.

Cassirer, Ernest

1925 Filosofía de las formas simbólicas. El pensamiento mítico. México: Fondo de Cultura Económica.

Corona Sánchez, Eduardo

2002 “Territorio y estado en Teotihuacan: los topónimos de Techinantitla”, Ideología y política a través de materiales, imágenes y símbolos. Memoria de la Primera Mesa Redonda de Teotihuacan, pp. 371-398, María Elena Ruiz Gallut (ed.). México: Consejo Nacional para la Cultura y las Artes, Instituto Nacional de Antropología e Historia y Universidad Nacional Autónoma de México, Instituto de Investigaciones Antropológicas e Instituto de Investigaciones Estéticas.

Edmonson, Munro S.

1982 The Ancient Future of The Itza: The Book of Chilam Balan of Tizimin. Austin: University of Texas Press.

Fash, William

2002 "El legado de Teotihuacan en la ciudad maya de Copán, Honduras", Ideología y política a través de materiales, imágenes y símbolos. Memoria de la Primera Mesa Redonda de Teotihuacan, pp. 210-370, María Elena Ruiz Gallut (ed.). México: Consejo Nacional para la Cultura y las Artes, Instituto Nacional de Antropología e Historia y Universidad Nacional Autónoma de México, Instituto de Investigaciones Antropológicas e Instituto de Investigaciones Estéticas.

Florescano, Enrique

2009 Quetzalcóatl y los mitos fundadores de Mesoamérica. México: Editorial Taurus (Colección Pasado y Presente). 
García Barrios, Ana

2005 “Chak Xib’ Chaahk: una revisión epigráfica e iconográfica”, Los investigadores de la cultura maya 13, tomo II, pp. 387-397. Campeche: Universidad Autónoma de Campeche.

2007 "El dios Chaahk en el Preclásico Maya”, Los investigadores de la cultura maya 15, tomo I, pp. 267-278. Campeche: Universidad Autónoma de Campeche.

2009 Chaahk, el dios de la lluvia en el periodo Clásico maya: aspectos religiosos y políticos, <http://eprints.ucm.es/8170/1/T30559bis.pdf>.

García Zambrano, Ángel J.

1994 "Early Colonial Evidence of Pre-Columbian Rituals of Foundation”, Séptima Mesa Redonda de Palenque (1989), pp. 217-227, Merle Greene Robertson y Virginia M. Fields (eds.). San Francisco: PARI.

Gendrop, Paul

2009 Diccionario de arquitectura mesoamericana. México: Editorial Trillas.

Girard, Rafael

1962 Los mayas eternos. México: Libro Mex.

Guenter, Stanley

2002 "Under a Falling Star: The Hiatus at Tikal", tesis de maestría. Australia: La Trobe University Bundoora.

Helmke, Christophe

2012a "Mythological Emblem Glyphs of Ancient Maya Kings", New World Archaeology, 3: 91-126.

2012b "Mytologia ja myyttinen aika / Mytologi och mytisk tid / Mythology and mythic time", Maya III: Life, Death, Time, pp. 160-185, Maria Didrichsen y Harri Kettunen (eds.). Helsinki: Didrichsen Museum of Art and Culture.

Hurst, Heather

2005 "San Bartolo, Petén: técnicas de pintura mural del Preclásico Tardío", XVIII Simposio de Investigaciones Arqueológicas en Guatemala, pp. 639-646, Juan Pedro Laporte, Bárbara Arroyo y Hector Mejía (eds.). Guatemala: Museo Nacional de Arqueología y Etnología, Ministerio de Cultura y Deporte, Instituto de Antropología e Historia y Asociación Tikal.

Kerr, Justin

s.f. $\quad$ A Precolumbian Portfolio, $<$ http://research.famsi.org/kerrportfolio.html $>$.

Lacadena García-Gallo, Alfonso

2008 "La escritura olmeca y la hipótesis del mixe-zoque: implicaciones linguíísticas de un análisis estructural del Monumento 13 de La Venta”, Olmeca. Balance y perspectivas. Memoria de la Primera Mesa Redonda, pp. 607-626, M. Teresa Uriarte y Rebeca González Lauck (eds.). México: Universidad Nacional Autónoma de México, Consejo Nacional para la Cultura y las Artes, Instituto Nacional de Antropología e Historia y New World Archaeological Foundation. 
Lacadena García-Gallo, Alfonso y Andrés Ciudad Ruiz

2009 "Migraciones y llegadas: mito, historia y propaganda en los relatos mayas prehispánicos en las Tierras Bajas”, Diásporas, migraciones y exilios en el mundo maya, pp. 57-78, Mario Humberto Ruz, Juan García Targa y Andrés Ciudad Ruiz (eds.). México: Universidad Nacional Autónoma de México y Sociedad Española de Estudios Mayas.

León Portilla, Miguel

2005 “Tonalamatl de los Pochtecas”, Arqueología Mexicana. Edición Especial Códi-

[1995] ces, 18.

Lombardo de Ruiz, Sonia

2006 "El estilo teotihuacano en la pintura mural", Pintura mural prehispánica en México, I, Teotihuacán, II. Estudios, pp. 3-64, Beatriz de la Fuente (coord.). México: Universidad Nacional Autónoma de México, Instituto de Investigaciones Estéticas.

Looper, Mattew G.

2003 Lightning Warrior. Maya Art and Kingship at Quirigua. Austin: University of Texas Press.

López Austin, Alfredo

2009 "El dios en el cuerpo", Dimensión Antropológica, 46: 7-45.

López Austin, Alfredo, Leonardo López Lujan y Saburo Sugiyama

1991 "El templo de Quetzalcóatl en Teotihuacan. Su posible significado ideológico", Anales del Instituto de Investigaciones Estéticas, 62: 35-52.

Love, Bruce

1994 The Paris Codex: Handbook for a Maya Priest, George E. Stuart (introd.). Austin: University Texas Press.

Martin, Simon y Nikolai Grube

2002 Crónica de los reyes y reinas mayas. Barcelona: Crítica.

Martos López, Luis Alberto

2010 "Objects cast into cenotes", Fiery Pool. The Maya and the Mythic Sea, pp. 223289, D. Finamore y S. D. Houston (eds.). New Heaven y London: Peabody Essex Museum and Yale University Press.

Mediz Bolio, Antonio (ed.)

2001 Libro de Chilam Balam de Chumayel. México: Consejo Nacional para la Cultura y las Artes.

Neurath, Johannes

2000 "El don de ver. El proceso de iniciación y sus implicaciones para la cosmovisión huichola", Desacatos, 5: 57-77. 
Nielsen, Jasper

2003 "Art of the Empire: Teotihuacan Iconography and Style in Earley Classic Maya Society (A.D. 380-500)", tesis para obtener el grado de Philosophy Doctor. Copenhagen: University of Copenhagen, Institute of History of Religions, Departament of American Indian Languages and Cultures.

Paxton, Merideth

2009 "Solar-Based Cartographic Traditions of the Mexica and the Yucatec Maya", Astronomers, Scribes and Priests: Intellectual. Interchange between the Northem Maya Lowlands and Highland Mexico in the late Posclassic Period, pp. 279-308, Gabrielle Vail y Christine Hernández (eds.). Washington D. C.: Dumbarton Oaks Research Library and Collection.

Price T., Douglas et al.

2014 "Kings and commoners at Copán: Isotopic evidence for origins and movement in the Classic Maya period", Journal of Anthropological Archaeology, 36: 32-47, $<$ www.elsevier.com/ locate/ jaa $>$.

Proskouriakoff, Tatiana

1960 "Historical implications of a Pattern o Dates at Piedras Negras, Guatemala", Ancient Antiquity, 25: 454-475.

Relaciones Histórico-Geográficas de la Gobernación de Yucatán

2008 vol. I, Mercedes de la Garza, Ana Luisa Izquierdo, María del Carmen León y Tolita Figueroa (eds.), María del Carmen León (paleografía), $2^{\mathrm{a}}$ ed. México: Universidad Nacional Autónoma de México, Instituto de Investigaciones Filológicas, Centro de Estudios Mayas (Serie Fuentes para el Estudio de la Cultura Maya, 1).

Saturno, William A., Karl Taube y David Stuart

2005a Los murales de San Bartolo, El Petén, Guatemala. Parte 1. El mural del Norte. Barnardsville: Center for Ancient American Studies.

2005b "La identificación de las figuras del muro oeste de Pinturas Sub-1, San Bartolo, Petén”, XVIII Simposio de Investigaciones Arqueológicas en Guatemala, pp. 647-655, Juan Pedro Laporte, Bárbara Arroyo y Héctor Mejía (eds.). Guatemala: Ministerio de Cultura y Deportes, Instituto de Antropología e Historia, Asociación Tikal y Foundation for the Advancement of Mesoamerican Studies, Inc.

Scandar, Florencia

2010 "La cuestión de la hierogamia en el Chilam Balam de Chumayel: diluvio y fundación. Una revisión crítica al pasaje del folio 25r”. Trabajo de investigación de Tercer Ciclo, programa de Doctorado del Departamento de Historia de América II (Antropología de América). Madrid: Universidad Complutense de Madrid, Facultad de Geografía e Historia.

Schele, Linda

1976 "Accesion Iconography of Chan Bahlum in the Group of The Cross at Palenque”, Segunda Mesa Redonda de Palenque, 1974, pp. 9-34, Merle G. Robert- 
son (ed.). Peeble Beach: Pre-Columbian Art Research Institute \& The Robert Louis Stevenson School.

Schele, Linda y Mary Ellen Miller

1986 The Blood of Kings: Dynasty and Ritual in Maya Art. New York: George Braziller y Kimbell Art Museum Fort Worth.

Schele Linda y Nikolai Grube

1997 "The Dresden Codex", Notebook for the XXI Maya Hieroglyphic Workshop at Texas. Austin: University of Texas, The Center for Mexican Studies.

Sharer, Robert J.

2003 "Founding Events and Teotihuacan Connections at Copán, Honduras", The Maya and Teotihuacan. Reinterpreting Early Classic Interaction, pp. 143-166, G. E. Braswell (ed.). Austin: University of Texas Press.

Sharer, Robert J. et al.

1999 "Continuities and Contrast in Early Classic Architecture of Central Copán", Mesoamerican Architecture as a Cultural Symbol, pp. 220-249, J. Karl Kowalskiew (ed.). New York y Oxford: Oxford University Press.

Smith, Michael E.

2006 "La fundación de las capitales de las ciudades-estado aztecas: la recreación ideológica de Tolán”, Nuevas ciudades, nuevas patrias. Fundación y relocalización de ciudades en Mesoamérica y el Mediterráneo Antiguo, pp. 257-290, M. Josefa Iglesias Ponce de León, Rogelio Valencia Rivera y Andrés Ciudad Ruiz (eds.). Madrid: Sociedad Española de Estudios Mayas.

Solís Alcalá, Ermilo

1949 Códice Pérez. Mérida: Imprenta Oriente.

Stuart, David

2000 "Las nuevas inscripciones del Templo XIX, Palenque”, Arqueología Mexicana, VIII (45): 28-33.

2005 The Inscriptions from Temple XIX at Palenque. A Commentary. San Francisco: The Pre-Columbian Art Research Institute.

2008 Copán Archaeology and History. New Finds and New Research. Sourcebook for the 32nd Maya Meetings. Assorted Materials to Accompany Lectures and Discussions. Austin: The University of Texas at Austin, Department of Art and Art History, The Mesoamerica Center.

Sugiyama, Saburo

1992 "Rulership, warfare, and human sacrifice at the Ciudadela: an Iconographic study of Feathered Serpent representations", Art, ideology, and the city of Teotihuacan, pp. 205-230, Janet Catherine Berlo (ed.). Washington: Dumbarton Oaks. 
Taube, Karl A.

1988 "Study o f Classic Maya Scaffold Sacrifice”, Maya Iconography, pp. 331-351, E. P. Benson y Gillett Griffin (eds.). New Jersey: Princeton University Press.

2010 "Where Earth and Sky meet. The sea and the sky in the contemporary Maya cosmology”, Fiery Pool: The Maya and the Mythic Sea, pp. 202-219, Daniel Finamore y Stephen Houston (eds.). Salem, Massachusetts: Peabody Essex Museum, Yale University Press.

Taube, Karl, William Saturno, David Stuart y Heather Hurst

2010 "Los murales de San Bartolo, El Petén, Guatemala, Parte 2: el Mural Poniente”, Ancient Mesoamerica, 10: 1-111.

Velásquez García, Erik

2002a "El Complejo Venus-Guerra-Tláloc y el arquetipo de Tulán-Suyuá”, La organización social entre los mayas. Memoria de la Tercera Mesa de Palenque, tomo II, pp. 229-271, Vera Tiesler, Rafael Cobos y Merle Greene Robertson (coords.). México: Consejo Nacional para la Cultura y las Artes e Instituto Nacional de Antropología e Historia.

2002b "Una nueva interpretación del Monstruo Cósmico maya", Arte y Ciencia, XXIV Coloquio Internacional de Historia del Arte, pp. 419-457, Peter J. Krieger (ed.). México: Universidad Nacional Autónoma de México, Instituto de Investigaciones Estéticas.

2007 "El mito maya del diluvio y la decapitación del caimán cósmico", The PARI, $\mathrm{XX:} 1-10$.

2010 "El antiguo futuro del K'atun. Historia y profecía en un espacio circular", Arqueología Mexicana, XII (103): 58-63.

Wagner, Elisabeth

2001 "Mitos de la creación y cosmografía de los mayas", Los mayas. Una civilización milenaria, pp. 281-293, Nikolai Grube (ed.). Colonia: Könemann. 